\title{
Biofilms by bacterial human pathogens: Clinical relevance - development, composition and regulation - therapeutical strategies
}

\author{
Adina Schulze ${ }^{1, \#}$, Fabian Mitterer ${ }^{1, \#}$, Joao P. Pombo ${ }^{1}$ and Stefan Schild ${ }^{1,2,3, *}$ \\ ${ }^{1}$ Institute of Molecular Biosciences, University of Graz, Humboldtstrasse 50, $8010 \mathrm{Graz}$, Austria. \\ 2 BioTechMed Graz, Austria. \\ ${ }^{3}$ Field of Excellence Biohealth - University of Graz, Graz, Austria. \\ \#A.S. and F.M. contributed equally to this work. \\ * Corresponding Author: \\ Stefan Schild, Humboldtstrasse 50, $1^{\text {st }}$ floor, 8010 Graz, Austria; Phone: ++43/ (0)316 3801970; E-mail: stefan.schild@uni-graz.at
}

\begin{abstract}
Notably, bacterial biofilm formation is increasingly recognized as a passive virulence factor facilitating many infectious disease processes. In this review we will focus on bacterial biofilms formed by human pathogens and highlight their relevance for diverse diseases. Along biofilm composition and regulation emphasis is laid on the intensively studied biofilms of Vibrio cholerae, Pseudomonas aeruginosa and Staphylococcus spp., which are commonly used as biofilm model organisms and therefore contribute to our general understanding of bacterial biofilm (patho-)physiology. Finally, therapeutical intervention strategies targeting biofilms will be discussed.
\end{abstract}

doi: $10.15698 / \mathrm{mic} 2021.02 .741$

Received originally: 08.09.2020;

in revised form: 08.01.2021,

Accepted 12.01.2021

Published 01.02.2021.

Keywords: biofilm-associated disease, nosocomial infections, Vibrio cholerae, Pseudomonas aeruginosa, staphylococci, treatment, biofilm.

\begin{abstract}
Abbreviations:
AIP - autoinducing peptide; CF - cystic fibrosis; COPD - chronic obstructive pulmonary disease; DGC - diguanylate cyclase; eDNA - extracellular DNA; EHEC - enterohemorrhagic E. coli; EPS extracellular polymeric substance; GIcNAc - N-acetyl-Dglucosamine; IBD - inflammatory bowel disease; MRSA methicillin-resistant S. aureus; MSCRAMM - microbial surface components recognizing adhesive matrix molecule; MSHA mannose sensitive hemagglutinin; PIA - polysaccharide intercellular adhesin; PDE - phosphodiesterase; QS - quorum sensing; SERAM - secretable expanded repertoire adhesive molecule; SRNA - small RNA; UPEC - uropathogenic E. coli; UTI urinary tract infection; UTR - untranslated region; VPS - Vibrio exopolysaccharide.
\end{abstract}

mental stressors, like hazardous chemical compounds, $\mathrm{pH}$ or physical damage. Differentiation of the microbes within the biofilm is aided by the biofilm's role as a mediator of cell-to-cell signaling.

Biofilms have been found to be ubiquitous in almost every environment. They can develop on all non-shedding surfaces in non-sterile liquid or wet environments sticking to both biotic and abiotic surfaces. Biofilms are being produced in the harshest environments, like in hot springs and deep-sea vents, on rocks and soil, the roots and stems of plants, on chitinous surfaces of aquatic animals, but also on many man made surfaces like pipes, the underside of ships, shower hoses etc. Biofilms represent an important element 
in many food chains in aquatic environment, where they are consumed by invertebrate, which are prey of fish.

Niels Høiby was amongst the first ones to recognize the relevance of biofilms in disease, which has been supported by increasing evidence since then [1]. Biofilms are involved in a wide variety of microbial infections in the body (Fig. 1). The National Institutes of Health (NIH) revealed that among all microbial infections, $60-80 \%$ are linked to biofilm formation [2]. Biofilm formation not only occurs on medical devices such as contact lenses, catheters, prostheses, heart valves and pacemakers, but also on a variety of body surfaces, including the skin or mucosal surfaces of the respiratory and digestive tract. Moreover, biofilms formed in the environment are not only a likely survival and persistence stage for facultative pathogens outside the host, but also a relevant reservoir for the initiation of new infections.
Several studies have demonstrated that bacteria associated in biofilms exhibit increased resistance to antimicrobial compounds than their individual, planktonic counterparts. Antibiotic resistance in biofilm infections is thought to be caused by a variety of factors, including metabolic alterations in bacteria within the biofilm, decreased penetration of antibiotics due to the extracellular matrix, inactivation of the antibiotic by compounds within the extracellular matrix, inoculum effects related to the very large number of bacteria in the biofilm relative to the available antibiotic molecules and increased exchange of bacterial resistance mechanisms as bacteria reside in close proximity to each other. Bacterial biofilms also facilitate immune evasion, for example by preventing phagocytosis or immune cell modulation and dysfunction via release of bacterial byproducts or toxins. Not surprisingly, hospitals have to deal with di-

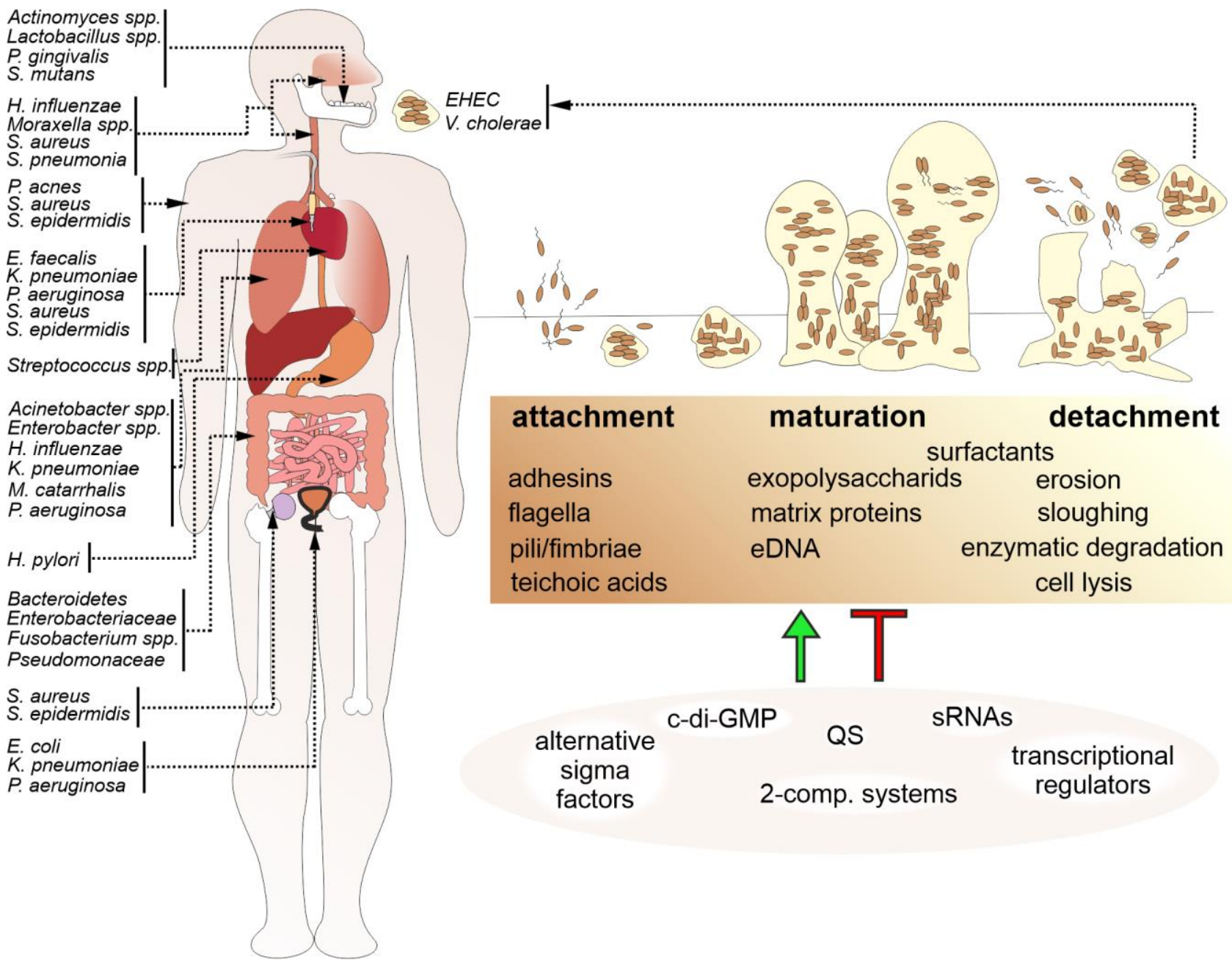

FIGURE 1: Biofilm formation is a common feature among bacterial human pathogens. Bacterial biofilms by human pathogens are found on various tissues of the human body, on medical devices, e.g. catheters or prostheses, and in the environment, representing a reservoir for new infections. A schematic overview indicating representative bacterial species associated with biofilm-related diseases and their occurrence in the body (arrows) is presented on the left. Biofilm formation (upper right) is a multistep process organized in an attachment, maturation and detachment phase. Biofilm formation is controlled and modulated by several factors including bacterial surface molecules, secreted matrix effectors, as well as environmental components and stressors. Thus, it is not surprising that bacterial biofilm regulation (lower right) involves the interplay of several positive and negative regulatory cascades including quorum sensing systems (QS), regulatory small RNAs (sRNAs), alternative sigma factors, two-component systems and second messengers, such as c-di-GMP. 
verse nosocomial infections caused by biofilm-forming bacterial pathogens that may severely affect patients suffering from predispositions like immune suppression or pre-existing diseases.

\section{ENVIRONMENTAL BIOFILMS AND THEIR IMPACT ON TRANSMISSION}

Between outbreaks facultative human pathogens may form biofilms outside of the host as a persistence mode. Importantly, biofilm formation can facilitate environmental survival and thereby allows to maintain a high infectious dose even for prolonged inter-epidemic periods. Thus, biofilm communities can represent a reservoir for future infections. Upon infection bacterial cells associated in biofilms are generally better protected against host defense mechanisms than their planktonic counterparts. Thus, biofilms could be a likely form in which opportunistic bacterial pathogens initiate the infection of a human host.

A representative example is Vibrio cholerae, the causative agent of the water borne diarrheal disease cholera. $V$. cholerae transits between the aquatic reservoir, where it forms biofilms on chitinous surfaces, and the human host, where it efficiently colonizes the intestinal tract. Importantly, not only intact biofilms, but also $\mathrm{V}$. cholerae cells dispersed from a biofilm are more infectious than freeliving, planktonic cells in the infant mouse model $[3,4]$. These results suggest the existence of factors specifically induced during biofilm formation that facilitate infection by $V$. cholerae even beyond the general idea of being better protected against host-derived antimicrobial factors within a biofilm. The impact of biofilms on transmission of $V$. cholerae is highlighted by the fact that a simple sari cloth filtration of drinking water, effectively removing biofilmassociated bacteria, reduced the number of cholera cases by approximately $50 \%$ in an Indian household study [5]. Thus, bacterial clumps or aggregates derived from mature biofilms are a likely form in which clinically relevant $V$. cholerae are taken up by humans, reinforcing the ecological and epidemiological role of biofilms.

Another example is the enterohemorrhagic Escherichia coli (EHEC) 0104:H4 isolate, which showed increased biofilm formation on fenugreek seeds and caused a severe outbreak in Germany in 2011 with a higher rate of hemolytic-uremic syndrome than any recorded before [6]. Genome-wide sequence analyses revealed that the outbreak EHEC strain had acquired the novel diguanylate cyclase, DgcX, synthesizing the biofilm-promoting second messenger c-di-GMP. Expression levels of DgcX are higher than any other known E. coli diguanylate cyclase and it consequently fuels enhanced biofilm formation [7]. One explanation for the unprecedented severity of this EHEC outbreak might be explained by the increased biofilm formation capacity of 0104:H4 providing a concentrative infective dose of the pathogen organized in biofilm aggregates.

Environmental biofilms in drinking water systems serve as a reservoir for the respiratory tract pathogen Legionella pneumophila, causative agent of Legionnaires disease, and opportunistic pathogens like Mycobacterium avium, repre- senting a health risk especially for immunocompromised patients. Especially in shower hoses Legionella spp. commonly produces biofilms, which are thought to promote the persistence and chlorine-resistance of the respiratory pathogen [8].

\section{CHRONIC AND ACUTE DISEASES CAUSED BY BIOFILM FORMING BACTERIA}

In contrast to biofilms formed outside of the human, bacterial biofilms can also be key factors for the fitness of pathogenic strains during host colonization. These biofilms can be either associated with medical devices or formed independently from foreign body material via colonization of host tissue, which is mainly observed along chronic infections.

\section{Medical device-related bacterial biofilms}

In clinics, bacterial biofilm formation on foreign body implants, such as catheters (intravascular and urinary), orthopedic inserts as well as dental and breast implants, can result in severe infections. Most infections acquired in a hospital environment (nosocomial diseases) are implantassociated infections and comprise $50-70 \%$ of all nosocomial infections [9]. Biofilms on medical devices pose a huge danger due to the high resistance to antibiotics, providing a reservoir of bacteria that can cause constant re-infections and chronic inflammation that can also lead to tissue damage, clogging of devices and general resistance to treatment. Important microorganisms involved in health care associated infections comprise Gram-positive bacteria, e. g. Staphylococcus aureus, Staphylococcus epidermidis, and Enterococcus faecalis as well as Gram-negative bacteria, such as E. coli, Klebsiella pneumoniae, Proteus mirabilis, and Pseudomonas. aeruginosa [10].

Roughly $80 \%$ of the microorganisms engaged in material-related contaminations are S. epidermidis and S. aureus, the latter especially in connection with surgical site infections, causing chronic wounds and other issues [11]. Notably, the majority of these isolates exhibit multidrug resistance, posing an immense challenge for therapeutical intervention in clinical practice [11].

Regarding vascular catheters, it has been documented that within the initial seven days after catheterization, extraluminal biofilm by S. epidermidis, S. aureus, E. faecalis, $K$. pneumoniae, and $P$. aeruginosa as well as the fungal pathogen Candida albicans considered a significant reason for catheter-related circulation system contaminations. In fact, vascular catheters that had been in situ for more than 30 days showed proof of heavy luminal colonization and biofilm development [12].

Along catheter-associated urinary tract infections, also known as CAUTIs, $P$. aeruginosa is one of the main causes in device related bacterial infections. Another dangerous biofilm producer linked to urinary tract infections, also known as UTIs, is $K$. pneumoniae. $63 \%$ of $K$. pneumoniae isolates from urine samples of catheterized patients suffering from UTIs were positive for in vitro biofilm production [13]. Chronic issues induced by device related infections 
are often due to the biofilm production enabling a tenacious and persistent colonization. As such, urinary catheters have to be exchanged at least every three months.

Biofilms also play a huge role in ventilator-associated pneumonia that occurs in patients requiring mechanical ventilation breathing machines in hospitals after surgery or various diseases, such as COVID-19. Due to the patients in need of ventilator assisted breathing often suffering from underlying immune or lung problems, ventilator-associated pneumonia can be a life-threatening condition. Ventilatorassociated pneumonia has been recorded as pervasive after $48-72 \mathrm{~h}$ in patients who have been intubated and are on mechanical ventilation. The increased danger of triggering ventilator-associated pneumonia following intubation with mechanical ventilation is six to 20 -fold. Especially endotracheal tubes are often associated with the development of biofilms and the methicillin-resistant $S$. aureus, also known as MRSA, and Gram-negative bacilli, such as, $K$. pneumoniae, E. coli, P. aeruginosa, and Acinetobacter baumanii [14 ]. Not surprisingly, mortality rates of ventilator-associated pneumonia are fundamentally higher than for UTIs and skin diseases [15].

\section{The respiratory tract}

The large mucosal surface makes the respiratory tract a preferred niche for biofilm growth, which can result in chronic inflammation of the mucosal tissue and reduced pulmonary function. For example, the widespread inflammatory disease chronic rhinosinusitis can be linked to presence of bacterial biofilms of the upper respiratory tract. S. aureus biofilms have been found on the nasal mucosal surface of $50 \%$ of patients [16], but additional causative agents include Streptococcus pneumoniae, Haemophilus influenzae and Moraxella catarrhalis [17]. The latter two tend to form inter-species biofilms, making treatment even more complicated.

Chronic phenotypes of pharyngitis and laryngitis are frequently associated with biofilm formation. A recent study identified biofilms in $62 \%$ patients with chronic laryngitis [18], consisting of pathogens like S. aureus, H. influenzae, C. albicans, Moraxella nonliquefaciens, Propionibacterium acnes, Neisseria meningitidis, and S. pneumoniae [18]. Substantial biofilm formation might explain the requirement for extended and multiple deployment of antibiotics to treat certain cases of chronic laryngitis.

Bacterial biofilms are also frequently associated with chronic infections of the lower respiratory tract, mainly observed in predisposed patients suffering from abnormal mucociliary clearance and other impaired host defenses, such as cystic fibrosis (CF). Chronic infections of the lung can exacerbate the primary disease and result in destructive inflammation. The altered viscosity, lower sheer and nutrient richness of patient's mucosa seems to promote biofilm formation [19]. While the lower respiratory tract of young patients with $\mathrm{CF}$ is prone to infections of $H$. influenzae and $S$. aureus, the main cause for infection in the lungs of adult CF patients is $P$. aeruginosa [20]. If initial colonization is not prevented, $P$. aeruginosa establishes permanently in the lungs and often mucoid mutants are selected that overproduce alginate. The conversion to mucoid strains seems to be driven be thy lung microenvironment and is not observed outside of the human body.

Notably, the extracellular polymers of $P$. aeruginosa biofilms are different for lung and UTIs described above as they contain higher amounts of the exopolysaccharide alginate and extracellular DNA (eDNA) [21, 22]. Alginate protects $P$. aeruginosa against phagocytosis, opsonization, antimicrobial compounds and clearance from the lungs [23]. On the other hand, alginate fuels an immune complex-mediated inflammation via a pronounced antibody response, which is characteristic for a Th2 polarized immune response [24]. Overall, this results in severe lung tissue damage. Notably, $P$. aeruginosa can reside asymptomatically within the human body until biofilm formation has reached a threshold and overwhelms the immune system. Mucoid strains are able to effectively colonize the lungs, stay persistent in the lungs of CF patients and are very difficult to treat. Consequently, biofilm production seems to be the most important virulence factor for $P$. aeruginosa associated with high mortality and morbidity in CF patients.

The exact mechanisms how $P$. aeruginosa biofilms are effectively protected against antibiotics is still a question of ongoing research. In the case of positively charged aminoglycosides, the negatively charged matrix components, e. g. alginate or eDNA, allow only slow diffusion into the biofilm and extend the adaption time for bacteria to mount a stress response [25]. Other antibiotics don't seem to be hindered by the barrier function of the biofilm matrix, but are yet still less effective against $P$. aeruginosa biofilms compared to planktonic bacteria. It is hypothesized that the biofilm provides a privileged environment for drugtolerant persister cells to survive, which can tolerate antimicrobials for prolonged periods [23].

Exposure of $P$. aeruginosa to hydrogen peroxide or activated polymorphonuclear neutrophils induces a mutation in the mucA gene, changing it to the characteristic mucoid phenotype. A Brazilian study revealed that this mutation can be found in $93 \%$ of mucoid $P$. aeruginosa isolated from CF patients [26]. In general, $P$. aeruginosa biofilm growth in CF lungs is associated with an increased frequency of mutations, slow growth and adaptation of the bacteria to the conditions in the lungs, and to antibiotic therapy. Thus, $P$. aeruginosa biofilms in CF patients can only be prevented by early aggressive antibiotic prophylaxis or therapy, before the biofilm is fully developed, or they can be treated by chronic suppressive maintenance therapy once the biofilm is already fully developed to extend lung function for several years [27].

Patients with chronic obstructive pulmonary disease (COPD) have a high risk of an acute excerbation triggered by bacterial infections caused by Pseudomonas, Klebsiella, Acinetobacter, Enterobacter, Moraxella catarrhalis and mixed infections such as Pseudomonas and Klebsiella or Pseudomonas and Acinetobacter [28].

Along these species enhanced biofilm production is often associated with clinical isolates. For example, around $85 \%$ of clinical isolates of $K$. pneumoniae exhibit robust 
biofilm production, which is also associated with multiple drug resistance [29]. Although biofilm production is often described in the context of infections of COPD affected lungs, direct demonstration of biofilm formation in lungs is mostly lacking and verification still remains mostly by indirect means.

\section{The urogenital tract}

A healthy urinary tract is occupied by a diverse natural bacterial flora resulting in relative high acidity by bacterial metabolism and thereby fairly protected from bacterial infections. Thus, main causes of biofilm-associated bacterial infections in the urogenital tract are device-related (see above). However, device-unrelated UTI through smear infection can occur. Notably, biofilm formation capacity of uropathogenic E. coli (UPEC) and S. aureus isolates was correlated with genitourinary tract infections in several studies [30,31]. Biofilm producing bacteria can exacerbate infections due to their relatively high antibiotic resistance, which may turn acute infections into chronic or reoccurring infections. For example, about $20 \%$ of women with acute cystitis (inflammation of the bladder) suffer from reoccurring UTI mostly caused by bacterial strains with strong biofilm production. Consistently, UPEC strains involved in reoccurring UTIs are better biofilm producers than UPEC strains causing only single episodes [32]. A recent study focusing on UTIs caused by $S$. aureus revealed that $69 \%$ of patients' isolates exhibit strong biofilm production, which resulted in increased resistance to nitrofurantoin, tetracycline, erythromycin and ciprofloxacin compared to nonbiofilm producing strains [30]. Concordantly, a study focusing on chronic bacterial prostatitis demonstrated that approx. $85 \%$ of 150 different bacterial isolates from chronic bacterial prostatitis patients were strong or moderate biofilm producers, including strains like E. faecalis, Staphylococcus spp., E. coli, and 20 other Gram-negative rods [33].

\section{Digestive tract}

The digestive tract of the human body is colonized with a vast quantity and diversity of microbes, with the highest concentration in the colon. Already more than 700 different bacterial species reside in the oral cavity of humans [34], which can initiate formation of dental biofilms, also known as dental plaque. The exact composition of the dental biofilm varies not only between different sites in the oral cavity, but also between individuals. Despite this, a core microbiome has been proposed, and includes species of the following genera: Streptococcus, Veillonella, Granulicatella, Neisseria, Haemophilus, Corynebacterium, Rothia, Actinomyces, Prevotella, Capnocytophaga, Porphyromonas, and Fusobacterium [35]

The dental biofilm can cause diseases in the teeth and their supporting tissues, i.e. dental caries and periodontal diseases. Regular removal of dental plaque is essential, as with increasing biofilm thickness bacteria are better protected against bactericidal activities of the saliva, which can no longer penetrate or reach the whole tooth [36].

Dental caries is characterized by a demineralization of the teeth without concurrent inflammation of surrounding tissues. However, if left untreated it may develop into inflammatory infections, such as pulpitis and apical periodontitis. While especially Streptococcus mutans, Actinomyces, and Lactobacillus spp. were previously regarded as responsible for caries, the list of caries-associated bacteria now includes species of the genera Actinomyces, Lactobacillus, Dialister, Eubacterium, Olsenella, Bifidobacterium, Atopobium, Propionibacterium, Scardovia, Abiotrophia, Selenomonas, and Veillonella in addition to carbohydratefermenting oral streptococci. Many of them are still not cultivatable in the laboratory. Usually when S. mutans colonizes tooth cavities caries follows after six to 24 months [37] The cariogenicity of $S$. mutans is due to the adherence properties of its secreted extracellular polymeric substances (EPSs), production of which is fueled in part by fructose [38].

Periodontal diseases, such as gingivitis and periodontitis are chronic inflammatory diseases of tissue around the teeth. Gingivitis is an inflammation of the gums, frequently observed as a response of the surrounding tissue to bacterial biofilm formation on the teeth. While under healthy conditions the gingival sulcus is colonized with predominantly Gram-positive streptococci at relative low level [39] the microflora can change within a couple of weeks in a complex mixture of mainly anaerobic Gram-positive and negative bacteria if biofilm formation is not prevented. Prolonged colonization of the oral cavity facilitates further invasion into the mucosal tissue and distribution of bacterial toxins. As a consequence, gingivitis can exacerbate into periodontitis, if no action in intervention of supragingival biofilm formation is taken. The growing biofilm can then extend into the periodontal pocket and manifests as a subgingival biofilm. Biofilms and the ongoing inflammation will gradually result in an opening of the periodontal pockets, disintegration of periodontal fibers and destruction of bones, which will loosen the teeth and finally results in their loss [40]. In contrast to gingivitis, the tissue destruction in periodontitis is irreversible. The subgingival biofilms are dominated by diverse Gram-negative rods like Prevotella spp., Porphyromonas gingivalis, and Fusobacterium nucleatum, but also include motile bacteria and spirochetes in deeper layers close to the epithelial surface [35].

Notably, the biofilm plaque serves as a constant reservoir of microbes as well as their inflammatory effectors, both of which can spread systematically in the body. Thus, dental biofilm bacteria are also directly and indirectly associated with several other systemic diseases such as cardiovascular diseases, atherosclerosis, infective endocarditis, aspiration pneumonia, diabetes mellitus, preterm birth, and low birth weight babies [41].

The gastric mucosa of approximately $50 \%$ of the human population is colonized by Helicobacter pylori [42]. Colonization with $\mathrm{H}$. pylori is linked to the initiation of peptic ulcer disease, corpus-predominant gastritis, and possibly also esophageal, adenocarcinomas [42]. Organization of $H$. pylori in biofilms has been visualized within the gastric mucosa [43]. One of the best studied virulence factors of $H$. pylori is urease, neutralizing the acidic conditions in the immediate gastric environment cells [44]. Notably, in patients 
suffering from peptic ulcer disease more than $95 \%$ of the mucosal gastric surface was covered by bacterial biofilms in urease-positive biopsies, while less than $2 \%$ of the surface was covered in urease-negative biopsies [45]. The importance of in vivo biofilm formation by $\mathrm{H}$. pylori is also highlighted by a recent study demonstrating that combinatory treatment with antibiotics coupled with the biofilm disrupting compound $\mathrm{N}$-acetylcysteine eradicated $\mathrm{H}$. pylori in $2 / 3$ of the patients, while a sole antibiotic therapy only cleared the infection in $1 / 5$ of the patients [46].

The residual intestinal mucosa is colonized with an enormous quantity and diversity of bacterial microbiota generally growing as healthy biofilm communities [47]. While defined pathogens cause distinct acute diarrheal diseases, the etiology and link to defined bacterial species for inflammatory bowel disease (IBD), irritable bowel syndrome and colorectal cancer is less clear. However, it is widely accepted that the intestinal microbiota can have beneficial as well as adverse effects on these disease states $[48,49]$. For example, in case of ulcerative colitis, a chronic relapsing form of IBD, a variety of biofilm-producing species including Fusobacterium spp., Shigella spp. and adhesive $E$. coli have been implicated to promote initiation and maintenance of disease [50]. Similarly, Crohn's disease has been associated with an overall increase of Enterobacteriaceae, Pseudomonas spp and Bacteroidetes, bacterial groups known to have members with good biofilm forming capabilities [51].

It seems reasonable, that bacterial biofilms can promote chronic colonization of these bacterial groups in gut. Moreover, the relatively high antimicrobial resistance of biofilms would explain the observed intractability of IBD to antibiotic therapy. Finally, biofilm matrix components may potentiate the proinflammatory response, which is a hallmark of IBD. Importance of bacterial biofilms in the pathogenesis of ulcerative colitis and Crohn's disease is indeed suggested by several reports, but we are just at the beginning to understand their impact on IBD and a comprehensive mechanistic understanding is currently lacking [52].

\section{Skin and wounds}

More than $60 \%$ of the microbial load on the human skin is composed of diverse biofilm producing bacteria. The predominant floras include Staphylococcus spp., Corynebacterium spp., and Propionibacterium spp. [53]. Biofilm producing skin bacteria cause a number of skin diseases, such as acne vulgaris caused by $P$. acnes, cellulitis, erysipelas and erythema nodosum caused by Streptococcus pyogenes, impetigo caused by S. pyogenes and S. aureus, necrotizing fasciitis caused by $S$. pyogenes, Klebsiella and Clostridium amongst others, staphylococcal scaled skin syndrome caused by S. aureus, chronic ulcers caused by Bacteroides, Clostridium and Streptococcus, and finally otitis externa and chronic wounds caused by $P$. aeruginosa. In general, biofilms increase the bacterial fitness against host immune defenses, bacteria, antibiotic therapy and general hygiene treatment. Bacterial biofilms also impact the risk of infection and progression of chronic wounds, as they have been associated with increased wound development and skin infections as well as improper wound healing due to chronic inflammation [54].

Many studies have confirmed that dermal tissues of chronic wounds contain several biofilm-forming bacteria, such as S. aureus, S. epidermidis, P. aeruginosa, E. coli, Enterobacter spp., E. faecalis, and K. pneumoniae. Almost $88-98 \%$ of wound infections have been found to be S. aureus positive [55]. S. aureus has fibrin receptors and thus can bind to fibrinogen, which can start biofilm formation. This affinity of $S$. aureus to bind to fibronectin, collagen and laminin makes it easy for the pathogen to colonize various host surfaces such as the skin. Patients having S. aureus biofilm infections require extended healing times due to delay in re-epithelialization of the infected tissue [56]. This can often exacerbate in patients that suffer from other diseases such as diabetes mellitus, which already damages the patients' tissue. S. aureus biofilms are hard to deal with due to their incredible resistance to antibiotic therapy and host immune response, with biofilm production even being promoted by the presence of ß-lactam antibiotics and cytokines [57]. Generally, antibiotic resistant $S$. aureus strains, such as MRSA, pose a worldwide problem in clinical medicine. $S$. aureus and $P$. aeruginosa are the two most common causes of chronic wound infections and are frequently co-isolated from the same wound. Chronic wounds don't always only contain chronic infection of a single bacterial strain, but can co-occur with several different biofilm producing strains such as $S$. aureus and $P$. aeruginosa. Analysis of 22 patient samples by using specific peptide nucleic acid and fluorescence in situ hybridization revealed that $P$. aeruginosa colonizes the deeper layers in the wound bed, while $S$. aureus was rather found on the wound surface [58]. Recent data indicates that both bacteria benefit from each other in coinfected wounds and synergistically increase antibiotic tolerance [59]. Wounds infected with $P$. aeruginosa are larger in size and require longer healing periods [58].

Emerging data also suggests that biofilm formation is a key colonization factor of the opportunistic pathogen $P$. acnes associated with the inflammatory disease acne vulgaris as well as invasive infections of skin, the cardiovascular system, soft and deep organ tissue and implant associated infections [60]. Most likely biofilm formation in sebaceous follicles results in elevated resistance of $P$. acnes against [61]. Biofilm-like aggregates of $P$. acnes are more frequently observed in skin biopsies of acne vulgaris patients compared to healthy control groups. Moreover, recent data suggests that biofilm formation by $P$. acnes is phylotype-dependent and isolates derived from invasive infections are associated with better biofilm production compared to healthy skin isolates $[62,63]$.

\section{Biofilms associated with invasive disease}

Invasive microbial infections occur at parts of the body that are generally considered germ free, e. g. the blood or other internal fluids and internal body sites such as the brain or the heart. Even though the infection routes can vary, some invasive microbial infections correlate with the ability of the responsible microbes to form biofilms. Well known 
biofilm associated invasive microbial diseases include endocarditis caused by Streptococcus, osteomyelitis mainly caused by $S$. aureus, otitis media caused by S. pneumonia and $H$. influenzae and meningitis caused by $A$. baumannii and $H$. influenzae.

Although bacterial endocarditis is mostly linked with heart implants, it can also occur through microbes reaching the heart either through wounds or in some cases through the bloodstream during the course of an invasive infection [64]. Microbes like Streptococcus spp. have fibronectin receptors facilitating biofilm formation on different tissues at various sites of injury, which can cause tissue damage of the valves and is especially detrimental in the case of endocarditis [65]. Open fractures, beside posing immediate danger to health, can also lead to chronic infections such as the bone disease osteomyelitis. S. aureus is predominantly present as a causative agent in cases of invasive osteomyelitis [66]. S. aureus has fibrin receptors and thus can bind to fibrinogen present in the bone matrix and can start biofilm formation. This affinity of $S$. aureus to bind to fibronectin, collagen and laminin makes it easy for the pathogen to colonize the bone by forming a biofilm [67]. One of the more predominant invasive diseases is otitis media, an infection of the inner ear. S. pneumonia and $H$. influenzae both cause otitis media, with more and more biofilm forming serotypes emerging as antibiotic treatment increases pointing to an important role of biofilms as protective factors in those cases [68].

Clinical isolates of invasive non-typeable $H$. influenzae and $A$. baumanii from bacterial meningitis patients, demonstrate higher biofilm production compared to isolates of these species, derived from carriers, chronic disease or respiratory tract infections [69, 70], which emphasizes the impact of biofilm formation for these pathogens to cause invasive diseases. Although biofilm formation is not directly linked to bacterial meningitis caused by Neisseria meningitidis, biofilm production is an important mucosal survival and persistence factor for the bacterium. Approximately $30 \%$ of carriage isolates are strong biofilm producers, a far greater percentage as observed for acute disease isolates. This suggests that biofilms might be important for the chronic carriage of the bacterium, which provides a reservoir for invasive meningococcal disease [71].

\section{BACTERIAL BIOFILM FORMATION AND COMPOSITION}

Based on the contribution of bacterial biofilms to bacterial infections, bacterial biofilm development and composition became a focal point of interest within the scientific community. Bacterial biofilm formation is a multistep process (Fig. 1): In general, initial surface attachment of planktonic bacteria is reinforced via adhesive surface appendages or proteins. Upon irreversible attachment and microcolony formation bacteria induce factors for production and secretion of extracellular matrix components, which results in the formation of a three-dimensional biofilm architecture. Finally, a mature biofilm requires dispersal to avoid harmful overgrowth, nutrient limitation and accumulation of metabolic waste products. Thus, some bacteria will detach from the mature biofilm to resume a planktonic lifestyle.

Formation and maintenance of biofilms require extracellular matrix components, which are responsible for surface adhesion, cell binding and preserving the biofilm architecture (Fig. 1, Table 1). Not only is there a vast diversity of the microbial community, but also the extracellular matrix shows species-specific variability. The EPS secreted by the constituent population of the biofilm is the major component of bacterial biofilms. The EPS mainly consist of polysaccharides, but may also contain other biomolecules like proteins, nucleic acids, glycopeptides, lipids, lipopolysaccharides as well as sequestered metals.

Many bacterial species are forming biofilms helping them to persist within the environment, protecting them against the host's immune system and therefore promoting infection and the development of disease symptoms. Here, the focus is laid on V. cholerae, $P$. aeruginosa, $S$. aureus and $S$. epidermidis due to their overlapping coverage of the mentioned biofilm functions (Table 1). V. cholerae biofilms formed in the aquatic ecosystem not only facilitate environmental persistence, but also impact transmission of the disease [72]. P. aeruginosa biofilms are found on medical devices as well as in the respiratory tract, i.e. in the lungs of CF patients [73]. Finally, biofilms of $S$. aureus and $S$. epidermidis are frequently associated with infections derived from indwelling medical devices and chronic wounds $[74,75]$. The selected candidates are well characterized biofilm producers as well as genetically modifiable, allowing deeper phenotypical analyses by the implementation of loss-/gain-of-function constructions.

\section{Attachment}

Bacterial adhesion on surfaces consists of reversible and irreversible stages and involves numerous factors, ranging from flagella, pili, fimbriae, lipopolysaccharides, lipoproteins, membrane proteins, adhesins, and eDNA.

The importance of flagella-mediated motility for initial attachment has been reported for several pathogens, including $V$. cholerae and $P$. aeruginosa $[76,77]$. V. cholerae uses its single, polar, $\mathrm{Na}^{+}$-driven flagellum to swim near the surface [78]. In close proximity to the surface hydrodynamic forces acting on the flagellum and cell body re-direct flagellar rotation into a clockwise direction resulting in circular swimming behavior [79]. Movement of $V$. cholerae becomes more restricted upon tethering to the surface by their flagella [79]. An elegant microscopical study by Utada and coworkers identified two motility modes named "roaming" and "orbiting" [80]. Besides flagellar motility these motion types require the mannose sensitive hemagglutinin type IV pili (MSHA) of $V$. cholerae promoting mechano-chemical attachment to surfaces. Weak interactions between the surface and MSHA enable bacteria to pass over the surface by long directional movements with only small curvatures, which define the "roaming mode". In contrast, the "orbiting mode" results from stronger interactions between the surface and MSHA visualized by tight, repetitive movements with near-circular orbits with 
TABLE 1. Overview of factors involved in the different stages of biofilm formation for the bacterial pathogens $V$. cholerae, $P$. aeruginosa, S. aureus and S. epidermidis discussed in this article. For details we kindly refer to the text (see chapter "Bacterial biofilm formation and composition").

\begin{tabular}{|c|c|c|c|}
\hline \multirow{2}{*}{$\begin{array}{l}\text { stage in biofilm } \\
\text { formation }\end{array}$} & \multicolumn{3}{|c|}{ bacterial pathogen } \\
\hline & V. cholerae & P. aeruginosa & S. aureus/ epidermidis \\
\hline attachment & $\begin{array}{c}\text { flagella motility, } \\
\text { type IV pili, } \\
\text { adhesins and } \\
\text { chitin-binding factors (e.g. } \\
\text { GbpA, ChiRP, FrhA, CraA) }\end{array}$ & $\begin{array}{l}\text { flagella/ twiching motility, } \\
\text { type IV pili, } \\
\text { Cup fimbrial adhesins and } \\
\text { lectins }\end{array}$ & $\begin{array}{l}\text { hydrophobic surface, } \\
\text { teichoic acids, } \\
\text { adhesins (e.g. Atl, Bap, } \\
\text { MSCRAMMs, SERAMs) }\end{array}$ \\
\hline maturation & $\begin{array}{c}\text { exopolysaccharide (VPS), } \\
\text { eDNA, } \\
\text { proteinaceous factors (RbmA, } \\
\text { RbmC, Bap1), } \\
\text { lipids }\end{array}$ & $\begin{array}{c}\text { exopolysaccharide (alginate, } \\
\text { Psl, Pel), } \\
\text { eDNA, } \\
\text { proteinaceous factors (e.g. } \\
\text { CdrA, LecA/B), } \\
\text { rhamnolipids }\end{array}$ & $\begin{array}{c}\text { exopolysaccharide (PIA), } \\
\text { eDNA, } \\
\text { proteinaceous factors [e.g. SasG, } \\
\text { Aap, and other adhesins (see } \\
\text { above)], } \\
\text { teichoic acids }\end{array}$ \\
\hline detachment & $\begin{array}{l}\text { nucleases (Dns and Xds), } \\
\text { proteases, } \\
\text { predicted sugar lyase (RbmD) }\end{array}$ & $\begin{array}{l}\text { Alginate lyase, } \\
\text { rhamnolipids, } \\
\text { cell lysis }\end{array}$ & $\begin{array}{c}\text { exoproteases (e.g. SspA/ Esp, } \\
\text { SspN/ SepA, SplA-F, ScpA) }\end{array}$ \\
\hline
\end{tabular}

high curvatures. More and more MSHA-surface interactions may tether orbiting cells tighter to the surface. Eventually, bacteria attach irreversibly to the surface and initiate production and secretion of the Vibrio exopolysaccharide (VPS) and biofilm matrix proteins resulting in microcolony formation followed by biofilm maturation (see below "Three-dimensional biofilm formation and maturation"). Notably, non-motile mutants lacking the major flagellin subunit FlaA are still capable of forming biofilms, but aggregate first in liquid culture before the clumps immobilize on surfaces resulting in altered biofilm architecture [79]. Moreover, flaA mutants show increased VPS production, which suggests that loss of the flagellum could induce biofilm formation [79]. Mutations in the flagellar motor complex negate the VPS overproduction of flaA mutants, indicating that the flagellar motor could act as a mechanosensor involved in the transition to the irreversible attachment state and initiation of matrix production [81].

It should be emphasized that environmental biofilm formation of $V$. cholerae in aquatic reservoirs occurs on chitinous surfaces, consisting of $\beta-1 \rightarrow 4$ linked $N$-acetyl-Dglucosamine (GICNAC) [82]. Several factors promoting attachment to chitin have been reported. For example, the GlcNAc-binding protein GbpA, which seems quite specific for GlcNAc-oligosaccharides, the chitin-regulated type IV pili ChiRP promoting competitive attachment to chitinous surfaces, and the MSHA pili, which generally facilitates adhesion to abiotic and chitinous surfaces, e.g. borosilicate, zooplankton and crab shells [83]. Moreover, the flagellumregulated hemagglutinin FrhA and c-di-GMP-regulated adhesin $\mathrm{A}(\mathrm{CraA})$ promote attachment and initial biofilm formation on chitin [84]. Thus, it is likely that these factors play more crucial roles for biofilm formation in the natural environment than what is currently suggested by laboratory studies mainly focusing on plastic material.

Similar to $V$. cholerae, $P$. aeruginosa is thought to get into close proximity to the surface via flagella-mediated motility. Non-flagellated mutants show reduced attachment especially under glucose- or amino acid-rich conditions $[76,85]$. However, in contrast to $V$. cholerae, $P$. aeruginosa reversibly attaches to surfaces in an upright (vertical) position and moves along random trajectories in "walking" mode using twitching motility mediated by type IV pili [86]. Mutants with a defective type IV pilus form aberrant biofilms [76]. Upon horizontal orientation to the surface, attachment transits into an irreversible state, but bacterial cells are still active for two-dimensional movement via twitching motility resulting in the organization of microcolonies. Comprehensive studies by the TolkerNielsen group suggest that $P$. aeruginosa also uses twitching motility for climbing up microcolonies formed by a subpopulation of non-motile cells to form the typical mushroom-like architecture of a mature biofilm [87]. P. aeruginosa recognizes surface attachment via the WspA protein, the membrane-bound receptor protein of the Wsp chemosensory signal transduction system that activates cdi-GMP synthesis upon surface contact [88]. As it will become evident below (see chapter "Regulation") the second messenger c-di-GMP is a central signal involved in biofilm regulation. In $P$. aeruginosa activation of the Wsp system and high c-di-GMP levels act positively on the production of CdrA (cyclic diguanylate-regulated two-partner secretion partner A) adhesin and Cup fimbrial adhesins, which promote surface adherence, as well as the exopolysaccharides Psl, Pel, and alginate, which are structural parts of the biofilm matrix [89-91]. 
Regarding biofilm formation of non-motile bacteria, the best studied representatives are probably $S$. aureus and $S$. epidermidis. In absence of a flagellum, adherence to hydrophobic surfaces is facilitated by the overall hydrophobic character of the bacterial envelope [74]. Furthermore, attachment to abiotic surfaces via hydrophilic and ionic interactions is promoted by defined surface factors, including wall teichoic acids, the major autolysin AtIE of S. epidermidis, its $S$. aureus homologue Atl, and the surface protein Bap of $S$. aureus, respectively [92, 93]. For example, at/E mutants in $S$. epidermidis exhibit a less hydrophilic surface and reduced biofilm formation capacity on polystyrene [94]. S. aureus $d t / A$ mutants lack an amino acid substitution in the wall teichoic acids, which increases their negative charge and thereby reduces initial attachment to hydrophobic glass or plastic surfaces [92].

Indwelling devices are rapidly surrounded by host tissue and coated with a host-derived matrix. To initiate biofilm formation, various staphylococcal surface factors not only adhere to host cell surfaces, but also bind extracellular host matrix components, e.g. fibronectin, fibrinogen, vitronectin, thrombospondin, bone sialoprotein, elastin, and collagen [92]. Aside of the above-mentioned wall teichoic acids, autolysins and Bap, these largely comprise the covalently-linked microbial surface components recognizing adhesive matrix molecules (MSCRAMMs) and the noncovalently surface-associated secretable expanded repertoire adhesive molecules (SERAMs). MSCRAMMs contain a conserved domain organization including an $\mathrm{N}$-terminal signal peptide, an outwardly exposed ligand-binding domain with directly repeated sequences, a hydrophobic membrane-spanning region, a C-terminal LPXTG motif required for cell wall anchorage, and a positively charged tail [95]. Cell wall anchorage is predominantly mediated by the SrtA sortase, a membrane-bound transpeptidase covalently linking the protein via the carboxyl group of threonine in the LPXTG motif to the amino group of the peptidoglycan [96]. Due to its conserved role in anchoring virulence factors to the cell wall, SrtA is suggested as a target for antivirulence drug development against staphylococci, enterococci and streptococci [97]. While S. aureus isolates encode for more than 20 MSCRAMMs, there are currently only twelve identified in S. epidermidis. Representative examples include the fibronectin-binding proteins FnbPA and FnBPB as well as the fibrinogen-binding proteins ClfA and ClfB of $S$. aureus or the accumulation-associated protein Aap and Bhp of S. epidermidis, which are highly homologous to SasG and Bap in S. aureus. Attachment flexibility and diversity is ensured as one MSCRAMM can bind several host factors and MSCRAMMs exhibit overlapping binding capacities. Not surprisingly, identification of the individual binding spectra of MSCRAMMs is still ongoing. SERAMs are a loosely defined group of secreted proteins, which bind back to bacterial surface by so far uncharacterized mechanism(s) and have relaxed binding specificity to host matrix factors [98]. Representative examples include the extracellular adherence protein Eap (also known as Map or P70) and the extracellular matrix and plasma binding protein Emb of S. aureus, which are absent in S. epidermidis [98].
Notably, S. epidermidis encodes for the membranespanning giant $1.1 \mathrm{mDa}$ fibronectin-binding protein Embp, while Ebh represents the homologue in $S$. aureus $[99,100]$. The current knowledge on staphylococcal adhesins was recently reviewed in detail by Heilmann et al., which we suggest for further reading [92].

\section{Three-dimensional biofilm formation and maturation}

Upon surface attachment bacteria alter their expression profile from a planktonic to a sessile lifestyle highlighted by the upregulation of components required for the biofilm matrix formation. The exact biofilm matrix composition differs between species, but generally includes a blend of various secreted biomolecules, such as polysaccharides, eDNA, proteins, lipids, and teichoic acids.

\section{Exopolysaccharides}

In many bacteria the development of a mature biofilm is associated with the production of exopolysaccharides, which are frequently the major component of the biofilm matrix.

For example, the VPS constitutes up to $50 \%$ of the mature Vibrio biofilm matrix and is required for the development of a three-dimensional biofilm [101, 102]. It is a polymer with a major repeating unit of $1 \rightarrow 4$ linked $\alpha$-L-GulpNAcAGly3OAc, $\beta$-D-glucose, $\alpha$-D-glucose and $\alpha$-D-galactose, with $\alpha$-I-GulpNAcAGly being an amide between C-6 of 2-acetamido-2-deoxy- $\alpha$-l-gulopyranosyluronic acid and an amino group of glycine, OAc being an $O$-acetylation and NAc being a $N$-acetylation [103]. Replacement of $\alpha$-D-Glc by an $\alpha$-D-GlcNAc in approximately $20 \%$ of the repeating units increases diversity [103]. The two nearby chromosomal loci vps-I and vps-II encode proteins for VPS biosynthesis and export, which are activated shortly after surface attachment [104, 105]. Notably, the $v p s-I$ and vps-II gene clusters are separated by the rbmA-E operon [106, 107], encoding for the two matrix proteins RbmA and RbmC (see below).

$P$. aeruginosa produces three different types of exopolysaccharides, i.e. alginate, Psl (polysaccharide synthesis locus) and Pel (pellicle) [108]. Alginate is an acetylated polymer of $\beta$-1,4-linked D-mannuronate and L-guluronate, which is synthesized by enzymes encoded by the algACD gene cluster [109]. It is not only the most important structural component of $P$. aeruginosa biofilms, but also acts as a barrier for antimicrobial compounds and facilitates immune evasion, thereby contributing to in vivo persistence during lung colonization [110, 111]. Biofilm formation of $P$. aeruginosa independent of alginate production highlights the existence of other polysaccharide matrix components, e.g. Psl and Pel $[112,113]$. While Pel is present in most $P$. aeruginosa strains, $\mathrm{Psl}$ is not wide-spread and is only produced by few $P$. aeruginosa strains, most notably by strain PAO1, but not PA14. Moreover, while Psl is found mainly at the outer surface of microcolonies, Pel is mainly located at the stem of the mushroom structure [114, 115]. The polysaccharide synthesis locus (ps/) harbors 15 genes involved in biosynthesis of the extracellular sugar polymer Psl, containing D-mannose, D-glucose and L-rhamnose 
[116]. Psl can be found in a larger cell-associated form and in a smaller soluble form. Especially, the smaller variant is thought to facilitate intercellular interactions and cellsurface attachment, but the exact mechanism yielding in the smaller variant is currently unclear [117]. Psl not only supports adherence during initial biofilm stages, but also contributes to the structural stability of mature biofilms. In doing so Psl interacts with other abundant biofilm matrix components including the matrix protein CdrA and eDNA $[89,118]$. Moreover, $P$. aeruginosa deposits a chemtrail of Psl as it moves on a surface, which guides subsequent cells to microcolony formation [119]. By exploiting the released DNA from the host's neutrophil extracellular traps, originally a defense system against pathogens, the eDNA-Psl interaction acts as biofilm scaffold and facilitates survival of $P$. aeruginosa during lung colonization [118]. Similarly, the Pel polysaccharide can also bind to eDNA due to its cationic amino sugars, which might explain why Pel can partially compensate a lack of Psl in $P$. aeruginosa biofilms [120]. Mutant strains lacking Pel are more susceptible to aminoglycoside antibiotics either because Pel binds aminoglycosides to reduce their activity or blocks their penetration into the biofilm [121]. The pel locus comprises a seven gene operon encoding for proteins with predicted functions for biosynthesis of the glucose-rich polysaccharide, but the exact chemical composition of Pel remains to be elucidated [120].

The major biofilm exopolysaccharide class in staphylococci is the polysaccharide intercellular adhesin (PIA) or, according to its chemical composition, a polymer of $\beta 1 \rightarrow 6$ linked $\mathrm{N}$-acetylglucosamines (PNAG), respectively [122]. It is considered to be the most important intercellular adhesin of staphylococci and is crucial for biofilm formation and virulence in S. epidermidis [123, 124]. PIA is synthesized by the proteins expressed from the icaADBC (intercellular adhesion) operon [124]. The $\mathrm{N}$-acetylglucosamine transferase IcaA, together with IcaD, synthesizes an $\mathrm{N}$-acetylglucosamine oligomer [125]. Chain growth is dependent on IcaC, which is suggested to act as PIA exporter. PIA is partially deacetylated on the bacterial surface by the PIA deacetylase IcaB [126]. This step is crucial for PIA retention and thus for the various functions PIA fulfills, not only biofilm formation, but resistance to antimicrobial peptides and neutrophil phagocytosis [126]. Moreover, partial loss of the $\mathrm{N}$-acetyl groups after secretion results in a cationic character facilitating electrostatic interactions with other extracellular molecules and adhesive properties of the biofilm matrix [126].

\section{eDNA}

It is becoming increasingly evident that eDNA is a polymeric matrix component of many bacterial biofilms and most likely originates from cell lysis [127]. The highly polymeric and anionic features of DNA allow cell-to-cell interactions via surface molecules in the matrix network [128]. Importantly, several bacteria secrete nucleases to degrade eDNA, which makes it a rather flexible structural compo- nent and enables bacteria to adapt to environmental changes via eDNA modulation.

For example, in $V$. cholerae biofilms eDNA levels are controlled by the extracellular endonuclease Dns and the exonuclease Xds, which is important for the development of a typical sponge-like biofilm architecture and detachment from mature biofilms [4]. Similar observations have been reported for $P$. aeruginosa with its secreted EndA nuclease, and for $S$. aureus releasing two thermostable nucleases Nuc1 and Nuc2 [129-131]. Due to extracellular nucleases and respective nucleotide uptake systems, eDNA can also serve as a carbon, nitrogen and phosphate source [132-134]. Not surprisingly, phosphate starvation activates nucleases in $V$. cholerae resulting in eDNA degradation and biofilm dispersion [132]. Indeed, this perception is confirmed by results showing that phosphate limitation negatively impacts biofilm formation in $V$. cholerae $[135,136]$. Besides its contribution to the biofilm architecture, eDNA is also a major proinflammatory factor of $P$. aeruginosa biofilms, limits penetration of antimicrobial compounds and allows horizontal gene transfer $[25,133,137]$.

\section{Matrix proteins}

Another important component of the bacterial biofilm matrix are proteins. Most proteins studied in the context of biofilm matrix contribute to the adhesive properties, stability and morphology of the biofilm. However, it should be noted that some proteins associated with biofilms exhibit enzymatic properties, e.g. sugar hydrolases, proteases and the above-mentioned nucleases, which actively degrade and modulate other matrix components resulting in biofilm reorganization and dispersal [4, 126, 129-131, 138-142].

In $V$. cholerae three major biofilm matrix proteins with predicted carbohydrate-binding domains have been identified, i.e. Bap1 (Biofilm-associated protein 1) as well as RbmA and RbmC (rugosity and biofilm structure modulator $A$ and C) [106]. Importantly, they exhibit individual spatiotemporal expression profiles and consequently fulfill different roles in biofilm formation, which was comprehensively characterized by an elegant microscopical study by Berk and coworkers [104]. The 26 kDa RbmA appears first on the cell surface after cells have attached to the surface and VPS production was initiated [104]. At later stages RbmA can be found on cell surfaces throughout the entire mature biofilm [104]. RbmA exhibits binding specificity to sugars including sialic acid derivates, which can be found in lipopolysaccharides as well as to galactose, which is a component of VPS $[105,143]$. This suggests that surfacelocated RbmA can act mainly as a scaffold protein mediating intercellular and cell-matrix interactions. Along initial biofilm formation, RbmA secretion is followed by the $75 \mathrm{kDa}$ Bap1, predominantly at sites were cells have contact with the surface or other bacteria. Even in mature biofilms, Bap1 is mainly found at the bottom of the biofilm with highest concentrations close to the founder cells, suggesting that it is predominantly secreted by these early biofilm members. Thus, anchoring the biofilm to the surface seems an important and unique feature of Bap1. Moreover, Bap1 was shown to bind outer membrane vesi- 
cles via the porin OmpT [144], which confers resistance to antimicrobial peptides. However, the impact of this interaction on biofilm formation is currently unknown. The last matrix protein to appear on discrete sites of the cell surface is RbmC, with a molecular weight of $104 \mathrm{kDa}$. Bap1 and $\mathrm{RbmC}$ share $47 \%$ similarity on the protein level and have several common domains. For example, both matrix proteins contain four Vibrio-Colwellia-BradyrhizobiumShewanella repeats (VCBS) forming two VCBS regions implicated to aid in cell adhesion [107, 145, 146]. Bap1 also contains four and RbmC two FG-GAP repeats, which are found in the eukaryotic integrin $\alpha$-chain important for attachment to the extracellular matrix [145, 147, 148]. Furthermore, Bap1 has one jacalin-like lectin domain with binding specificity to galactose, mannose and glucose, while RbmC has two such domains [105, 149]. These sugars are also present in the Vibrio exopolysaccharide matrix suggesting interactions between VPS and both proteins in the Vibrio biofilm [105]. Indeed, Bap1 and RbmC can partially complement each other, although they are not functionally redundant [107]. Both proteins form flexible envelopes around the cells in the biofilm, but only Bap1 remains at high concentrations on the basis of the biofilm, while RbmC seems rather important for VPS interactions throughout the biofilm [104].

Notably, export of the three matrix proteins, RbmA, Bap1 and RbmC, as well as of the chitin-binding protein GbpA relies on the type II secretion system, which is also responsible for cholera toxin secretion during intestinal colonization [150,151]. This highlights the importance of this secretion machinery for $V$. cholerae physiology. Type II secretion requires proper protein folding in the periplasm under assistance of chaperones before the machinery recognizes the folded substrates for further translocation across the outer membrane. Interestingly, a recent study indicated that O-glycosylation of periplasmic chaperones impacts the type II-dependent secretion of several proteins, including RbmA, and consequently alters biofilm formation [152].

$P$. aeruginosa biofilms also harbor several matrix proteins, including the Psl-binding protein CdrA as well as the lectins LecA and LecB (also known as PA-IL and PA-IIL) [89, 153]. The matrix protein CdrA is expressed in $P$. aeruginosa biofilms in response to high levels of 3,5,-cyclic diguanylate (c-di-GMP) and binds to the exopolysaccharide Psl, most likely via mannose residues [89]. CdrA contains several potential binding domains, including a carbohydratedependent activity domain, a glycine-rich sugar-binding domain and an arginine-glycine-aspartate motif that may facilitate adhesion to integrin [89]. Due to its Psl interaction CdrA mediates cell autoaggregation reinforcing biofilm integrity and development on abiotic surfaces [89]. Notably, CdrA exists in two forms, a $220 \mathrm{kDa}$ cell-associated version and a soluble $150 \mathrm{kDa}$ processed variant, which misses approximately $45 \mathrm{kDa}$ on the $\mathrm{N}$-terminal end and $35 \mathrm{kDa}$ on the C-terminal end, respectively [89]. Functional differences between the two variants remain to be elucidated.
In addition to their cytotoxic activity during lung infection, LecA and LecB also contribute to biofilm formation [154-157]. LecA is required for biofilm formation on abiotic surfaces, such as plastic or stainless steel, and shows high binding affinity to hydrophobic galactosides, but also binds sugars like $\mathrm{N}$-acetyl-D-galactosamine and glucose [157159]. LecA is a tetrameric protein that consists of four $12.8 \mathrm{kDa}$ subunits [160]. Each monomer contains a calcium-dependent ligand-binding site for galactose as well as an additional independent binding site for glucose [159]. However, it is not yet clear whether LecA interacts with Psl, Pel or both. In contrast, LecB is rather required for biofilm formation on glass surfaces and binds to a number of monosaccharides, with high specificity to L-fucose [154]. Nevertheless, LecB readily interacts with mannose and galactose residues of Psl [161]. Similar to LecA, LecB is a tetramer assembled out of four $11.7 \mathrm{kDa}$ subunits with ligand binding pocket stabilized by two calcium ions [162]. LecB is localized to the outer membrane with the outer membrane porin OprF being an essential ligand for its membrane association [163].

Several staphylococcal surface proteins have been attributed adhesive properties along biofilm formation. Along the ones already mentioned in the attachment section above, cell wall-anchored SasG of $S$. aureus and its homologue Aap in S. epidermidis exhibit self-polymerizing activity facilitating zinc-dependent intercellular interactions [164]. Interestingly, SasG and Aap can also interact with each other allowing interspecies biofilm formation [165]. Impact on pathogenesis in a mouse catheter implant infection model was demonstrated for the surface proteins Bap and Spa in S. aureus $[166,167]$. Members of the Bap protein family are large proteins found in the biofilm matrix of several Gram negative and positive bacteria, including S. aureus and S. epidermidis [166, 168]. The $239 \mathrm{kDa}$ Bap of $S$. aureus exhibits four regions (A-D) that contain repeats as well as a $\mathrm{N}$-terminal putative Sec-dependent signal sequence. Region $A$ consists of two 32 amino acid repeats followed by region B without repeats [166]. Interspecies biofilm formation might be mediated by heterodimerization of Bap orthologs via a putative dimerization domain located in regions $A$ and $B$ [169]. The central region $C$ contains thirteen 86 amino acid repeats, which are predicted to fold in a $\beta$-sandwich and mediate adhesion. Finally, region $D$ contains three 18 amino acid repeats and the cell-wall anchoring LPxTG motif at the C-terminus [166].

\section{Lipids, surfactants and teichoic acid}

Lipids and biosurfactants are also present in the extracellular matrix, e.g. in $V$. cholerae it can amount to $33 \%$ of the entire biofilm extracellular matrix [170]. Especially biosurfactants are important for bacterial attachment and dispersal from oil droplets. Generated by microorganisms at the air-water interface, they influence surface tension and gas exchange between estuarine waters and the atmosphere [171]. Rhamnolipids, which act as surfactants, can be found in the extracellular matrix of $P$. aeruginosa [172]. The quorum sensing (QS)-controlled $r h / A$ gene encodes for a rhamnosyltransferase that is exclusively involved in 
rhamnolipid biosynthesis [173]. Rhamnolipids play a crucial role in shaping the biofilm architecture by facilitating surface-associated bacterial migration, the formation of mushroom-shaped structures and keeping the water channels of the biofilm open during matrix maturation [172].

In staphylococcal biofilms, teichoic acids are crucial for adhesion, biofilm formation and host colonization [174, 175]. Two different forms exist: wall teichoic acids, consisting of alternating phosphate and ribitol, are covalently linked to peptidoglycan in the cell wall, while lipoteichoic acids, exhibiting alternating phosphate and glycerol, are surface-anchored via a lipid moiety intercalating with the cytoplasmic membrane [92]. The high charge of teichoic acids is critical for $S$. aureus biofilm formation on abiotic surfaces. Wall teichoic acids lacking D-alanine, and thus increasing the net negative charge, decrease the ability of the microorganism to form in vitro biofilms on plastic surfaces [174]. In S. epidermidis wall teichoic acids induce adhesion to immobilized fibronectin [176].

\section{Detachment/dispersal}

Finally, a vital biofilm community can only persist when a certain population of bacterial cells are allowed to detach from the mature biofilm community leaving a favorable environment for the remaining residents. Dispersed bacteria can either find a new substratum to attach and initiate biofilm formation or transit into a planktonic lifestyle to explore other niches. Biofilm dispersion ranges from continuous detachment of single cells, also known as erosion, to rapid release of multicellular clumps of the biofilm community, also called sloughing. Dispersal can either be an active mechanism or passively mediated by physical stressors such as shear forces. Active detachment relies on differential gene expression triggered by diverse environmental cues like temperature and $\mathrm{pH}$ shifts, nitric oxide, starvation, oxygen deprivation, and other stressors. During dispersal genes involved in cell motility and biofilm matrix degradation are generally induced, while attachment and EPS production genes are repressed [177].

$V$. cholerae biofilms grown on chitinous surfaces disperse within minutes upon removal of $\mathrm{Ca}^{2+}$, highlighting the importance of the environmental conditions for biofilm development [178]. Recently, Singh et al. observed that mature biofilms in flow cells disintegrated rapidly upon stopping the flow, which results in nutrient depletion as well as accumulation of QS autoinducers [179]. These changes result in altered gene expression mainly mediated via RpoS, an alternative sigma factor rising upon nutrient limitation and HapR, the master regulator of QS with increasing cellular levels upon high cell density [180, 181]. Indeed, mature biofilms with a critical size beyond approximately $18 \mu \mathrm{m}$ show high levels of RpoS and HapR, both required to initiate dispersal $[179,180]$. Furthermore, the extracellular nucleases Dns and Xds have been demonstrated to be essential for detachment [4]. Notably, biofilm clumps of the $x d s / d n s$ double mutant were impaired for in vivo colonization, while wild type (WT) biofilm clumps outcompeted their planktonic counterparts [4]. This strengthens the current dogma that biofilm-derived aggregates are a likely form in which $V$. cholerae is ingested by the host, but also highlights the importance of biofilm dispersal in the gut to achieve full colonization fitness. Finally, RbmD, encoding a putative polysaccharide lyase, has been hypothesized to have a role in VPS degradation resulting in detachment as a rbmD mutant shows increased biofilm formation [107]. A decrease of the second messenger c-diGMP liberates the LapG protease from the c-di-GMP receptor LapD, which results in proteolytic cleavage of the surface adhesins CraA and FrhA, promoting biofilm detachment [84].

Low c-di-GMP levels is also considered a signal for biofilm dispersion in $P$. aeruginosa, although the exact mechanism remains to be elucidated. Alginate lyase induction in $P$. aeruginosa resulted in a three-fold reduction of the exopolysaccharide alginate and increased the number of detached cells by nine to 16-fold [182]. Furthermore, $P$. aeruginosa biofilm dispersal is influenced by carbon availability [183]. Biofilms grown on glutamate medium induced dispersal upon excessive carbon availability [183] The extent of released cells correlated with increased expression of flagella and downregulation of twitching motility. Indeed, flagellated subpopulations leaving $P$. aerugino$s a$ biofilms have been described [184]. Although rhamnolipids are important surfactants along $P$. aeruginosa biofilm development, increased levels can result in bacterial dispersal $[184,185]$. Cell lysis may also play an important role in biofilm dispersal. In twelve-day old $P$. aeruginosa biofilms dead cells in the center mount up to $50 \%$, which could be partially attributed to prophage activation [186].

Secretion of exoproteases seems to be the main detachment strategy of S. aureus and S. epidermidis. S. aureus secrets seven serine proteases (SspA and SplA-F), two cysteine proteases ( $\mathrm{SspB}$ and $\mathrm{ScpA}$ ) and one metalloprotease (Aur) [187]. SspA degrades the adhesins FnBPs and Bap and aureolysin degrades ClfB and Bap mediating biofilm dispersal [188]. S. epidermidis encodes at least three secreted proteases: a homologue of the cysteine protease SspB, the SepA metalloprotease and Esp, a homologue of the serine protease SspA [189]. SspB and ScpA, also called staphopains, are shown to disrupt the biofilm matrix, however, the target proteins are yet to be characterized [190]. Proteases are induced by the $S$. aureus QS-system agr, which is activated upon an autoinducing peptide (AIP) [191]. In addition, non-native proteases are likely to impact S. aureus biofilm development as most proteases seem to have rather relaxed target specificity [192]. For example, the serine protease Esp of $S$. epidermidis is able to cleave an array of $S$. aureus biofilm proteins, including Eap, FnBPA and Atl and consequently disperses $S$. aureus biofilms [193, 194]. Notably, S. aureus and S. epidermidis lack enzymes degrading the exopolysaccharide PIA, although such effectors exist in nature. For example, the Actinobacillus actinomycetemcomitans enzyme dispersin B can disperse PIAdependent staphylococcal biofilms by hydrolysis of the glycosidic linkages, which increases their susceptibility to antimicrobial treatment [195]. 


\section{BIOFILM REGULATION}

The regulation of biofilms involves a complex network of regulatory cascades including QS-systems, regulatory small RNAs (sRNAs), alternative sigma factors, two-component systems and second messengers, such as c-di-GMP (Fig. 1). In this chapter we will highlight the most important regulatory circuits controlling biofilm formation in the pathogens $V$. cholerae, P. aeruginosa, S. aureus and S. epidermidis.

\section{Quorum sensing (QS)}

QS is a bacterial system playing an important role in cell-tocell communication and inter-kingdom signaling [196]. Bacteria produce extracellular signaling molecules, i.e. autoinducers, which accumulate with increasing cell density. After reaching a threshold concentration, autoinducers are recognized by receptors located on the cell membrane and orchestrate gene expression that underlie collective behaviors. This auto-regulation enables the bacteria to synchronize within its sessile microbial community in order to optimize adaption and resilience (e.g. luminescence, virulence, and biofilm formation) [197].

$V$. cholerae encodes four autoinducer receptors comprising the membrane-bound CqsS, LuxPQ, and CqsR as well as the cytoplasmic VpsS [198]. CqsA synthesizes the cholera autoinducer 1 (CAl-1), which binds to its cognate membrane-bound receptor CqsS, while LuxS produces the autoinducer 2 (Al-2) binding to the receptor LuxPQ [198]. Recent studies suggest that ethanolamine serves as a ligand for CqsR, while autophosphorylation of VpsS is blocked by nitric oxide via the nitric oxide-responsive hemoprotein NosP [199, 200]. Importantly, all four autoinducer receptors feed into the same phosphorelay pathway and converge at the histidine phosphotransfer protein LuxU [198]. Briefly, at low concentrations of autoinducers indicating low cell densities the kinase activity of the autoinducer receptors results in phosphorylation of LuxU, which in turn phosphorylates the transcriptional regulator LuxO [201]. Phosphorylated LuxO together with the alternative sigma factor RpoN activates transcription of the sRNAs Qrr1-4, which block the expression of HapR [201]. Notably, the transcription factor HapR is the main repressor of biofilm formation via transcriptional silencing of vps gene expression [201]. Moreover, HapR alters expression of several enzymes involved in biosynthesis of the second messenger c-di-GMP, which facilitates biofilm formation (see below). At high cell densities, the QS cascade decreases intracellular c-di-GMP levels via HapR [202]. Not surprisingly, hapR mutants show excessive exopolysaccharide production and uncontrolled biofilm formation [181]. Notably, several additional regulatory systems have been shown to influence the QS-HapR cascade, e.g. the two-component system Va$\mathrm{rA} / \mathrm{S}$, the regulatory protein VqmA, cAMP and the alternative sigma factor RpoS, some of which will be discussed in the sections below [203-205]. In summary, QS in V. cholerae downregulates biofilm formation at high cell densities.

In $P$. aeruginosa three interconnected QS signaling networks have been discovered, i.e. the las-, the $r h /-$, and the PQS-system [206]. Lasl produces the acylhomoserine lactone $\mathrm{N}$-(3-oxododecanoyl)-homoserine lactone (OdDHL), which acts as autoinducer and binds to its cognate receptor LasR. Similarly, Rhll synthesizes the autoinducing molecule $\mathrm{N}$-butyrylhomoserine lactone (BHL), which is recognized by RhIR. Notably, LasR and RhIR target genes constitute about $10 \%$ of the $P$. aeruginosa genome and thus both QS systems account for a majority of biofilm- and virulence-related processes in the pathogen [207]. PQS, structurally identified as 2-heptyl-3-hydroxy-4-quinolone, is synthesized by PhnAB and PqsABCDH from chorismate and was originally studied as an antibacterial compound [208]. Having a hydrophobic character PQS is transported via outer membrane vesicles [209]. Interestingly, PQS is a versatile compound. It not only activates genes involved in biofilm formation and virulence by binding to its receptor PqsR, but can also stimulate vesiculation by curvature induction of the outer membrane. Moreover, PQS chelates ferric iron and mediates iron acquisition. Undoubtedly, QS signaling networks of $P$. aeruginosa are interconnected in a hierarchical order (for an overview see [206]): LasR positively regulates the Rhl- and PQS-system, RhIR negatively regulates the PQS-system and PQS positively influences the RhL-system. QS signaling in $P$. aeruginosa impacts biofilm formation in multiple ways, e.g. via control of swarming and twitching motility, rhamnolipid biosynthesis, Psl expression, autolysis resulting in eDNA release and expression of the lectins LecA and LecB [206, 210-212].

In staphylococci, two regulatory QS systems have been described. The accessory gene regulator (Agr) system is considered to be the major QS regulator system in Grampositive bacteria, while the LuxS system of staphylococci seems to play a minor role [213]. The agr locus contains two transcriptional units, RNAll and RNAIII, with their promotors P2 and P3, respectively [214]. The RNAll cluster consists of four genes, agrB, agrD, agrC, and agrA [214]. The peptide precursor for the extracellular QS AIP of the Agr system is encoded by agrD [215]. In most staphylococ$\mathrm{ci}$, including $S$. aureus and S. epidermidis, the mature AIP contains a thiolactone modification between the central cysteine and the C-terminus of the seven to nine amino acid long AIP. This modification is added by the transmembrane endopeptidase AgrB, which additionally catalyzes the C-terminal cleavage and export of the AIP into the extracellular milieu [216]. After secretion AIP is finally trimmed by the type I signal peptidase SspB [217]. AIP activates the two-component signal transduction system AgrC/A, composed of the transmembrane histidine kinase sensor AgrC and its associated response regulator AgrA [218]. AIP signaling results in phosphorylated AgrA, which promotes transcription of the RNAII and RNAIII regions as well as the genes encoding the phenol-soluble modulins PSM $\alpha$ and PSM $\beta$ [219-221]. The latter represent surfactants required along the development of mature biofilms and detachment reducing the non-covalent interactions between cells and the biofilm matrix components [222, 223]. Regulation of RNAIII by AIP provides a positive autofeedback loop, as the RNAll cluster is responsible for AIP synthesis [214]. In contrast, RNAIII is a multifunctional reg- 
ulatory RNA and represents the Agr intracellular effector molecule controlling expression of downstream targets [224]. Aside from virulence-associated factors, RNAIII regulates several biofilm-relevant factors like MSCRAMMs, nucleases, and peptidases [167, 225]. Notably, RNAlll also acts as a mRNA encoding for the $\delta$-toxin (also known as $\delta$ hemolysin) [226]. In general, the Agr QS system seems to have an inhibitory role on biofilm development as agr mutants exhibit thicker, less structured biofilms [227-229]. However, enhanced biofilm formation can be beneficial in clinical settings. Thus, mutants with impaired Agr signaling are frequently isolated from indwelling devices [227]. As in $V$. cholerae, the LuxS system uses the Al-2 autoinducer, suggesting a role in interspecies communication [230]. The LuxS system of $S$. aureus has been implicated in the regulation of biofilm formation, virulence, capsule synthesis, and antibiotic susceptibility [231-233]. Similarly, LuxS of S. epidermidis affects a number of genes, including biofilm exopolysaccharide biosynthesis gene clusters [234]. However, several reports argue that the observed phenotypes in mutants with an impaired LuxS system are due to its primary role in metabolism [234, 235]. Thus, LuxS as a QS regulatory system in staphylococci remains under debate.

\section{Cyclic-di-GMP}

The second messenger bis-(3'-5')-cyclic dimeric guanosine (c-di-GMP) is a central regulatory element mediating bacterial transitions between planktonic and sessile lifestyles. In general, c-di-GMP represses motility and virulence, but promotes biofilm formation, e.g. via activation of extracellular matrix production and adhesins [236]. Along biofilm development c-di-GMP can impact initial attachment, maturation, and detachment. Intracellular levels of c-di-GMP are controlled by two enzyme classes, diguanylate cyclases (DGCs) with their catalytical domain GGDEF, which synthesize c-di-GMP from GTP, and EAL- or HD-GYP-domain containing phosphodiesterases (PDEs), which hydrolyze c-diGMP to 5'-phosphoguanylyl-(3'-5')-guanosine or GMP, respectively [237]. Regulation of gene expression via c-diGMP can be mediated at multiple levels, including (i) allosteric regulation of enzyme activity, (ii) binding and conformational change of transcription factors, and (iii) interactions with the untranslated regions of mRNAs, also known as riboswitches.

V. cholerae encodes for 31 GGDEF-domain, twelve EALdomain, nine HD-GYP-domain containing proteins [238]. Moreover, ten additional proteins contain both, an GGDEFand EAL-domain, but mostly exhibit only one activity as one domain is generally degenerated [238]. Transcriptional and post-transcriptional regulation of these proteins enable $V$. cholerae to modulate intracellular c-di-GMP levels. In addition to environmental signals, such as temperature, polyamines and bile salts, the transcriptional regulators of biofilm formation, i.e. HapR, VpsT and VpsR have been reported to regulate defined sets of PDEs and DGCs [203, 239-242]. VpsT and VpsR, which are central transcriptional response regulators of biofilm formation, induce DGCs and repress PDEs, thereby generating high c-di-GMP levels promoting biofilm formation [203, 240]. In contrast, HapR was shown to upregulate PDEs and downregulate DGCs, resulting in reduced c-di-GMP levels and less biofilm formation [202, 240]. Moreover, LuxO and the sRNAs Qrr1-4 also regulate some PDEs and DGCs in an HapRindependent manner [243]. Expression changes upon varying c-di-GMP levels are mediated by c-di-GMP-dependent riboswitches or c-di-GMP-binding proteins, e.g. transcriptional regulators FlrA, VpsR and VpsT as well as PilZ proteins [244-247]. PilZ-domain proteins represent a unique cdi-GMP binding protein family with an RXXXR and DXSXXG motif and are named after the type IV pilus control protein first identified in $P$. aeruginosa [248]. In V. cholerae, c-diGMP represses transcription of flagellar genes by binding the flagellar regulatory protein FlrA, altering its activity, and thus inhibit its ability to activate flagellar gene expression [249]. VpsR binds c-di-GMP and upregulates the vpsT, the vps-I and -II gene clusters, encoding VPS synthesis and export, as well as the epsC-N operon, encoding the type II secretion machinery, required for secretion of biofilm matrix proteins, in a c-di-GMP-dependent manner [240, 250] VpsT can undergo c-di-GMP-dependent and -independent dimerization, while c-di-GMP binding stabilizes the VpsT dimer [246]. VpsT facilitates expression of matrix proteins, i.e. RbmC and Bap1, and acts in concert with VpsR to activate the vps genes [240,251,252]. VpsR is also the main transcriptional regulator of the CraA adhesin [84]. Notably, mutual transcriptional activation of $v p s R$ and $v p s T$ also depends on c-di-GMP, antagonizing the H-NS repression of vps and rbm genes [253]. Additionally, V. cholerae expresses five PilZ-domain proteins, which affect virulence, motility, and biofilm formation [244]. However, the molecular mechanism how c-di-GMP sensing by PilZ proteins is transferred to changes in the transcriptional profile remains to be elucidated.

The second messenger c-di-GMP also promotes biofilm formation in $P$. aeruginosa. Biofilms of this pathogen contain on average 75-110 pmol c-di-GMP per mg of total cell extract, which is approximately four-fold higher compared to planktonic cells [254]. Similar to $V$. cholerae, $P$. aeruginosa encodes a diverse set of DGCs and PDEs including 18 GGDEF-domain-, five EAL-domain, three HD-GYPdomain-containing proteins as well as 16 proteins with GGDEF- and EAL-domains [255]. Along the latter, "hybrid" proteins with DGC and PDE activity exist in $P$. aeruginosa [256]. For example, MucR exhibits DGC activity in planktonic cells promoting alginate biosynthesis, whereas in biofilms PDE activity dominates resulting in nitric oxide- or glutamate- induced biofilm dispersal [257]. The first characterized DGC of $P$. aeruginosa is WspR, which is named after the wrinkly spreader phenotype forming upon an increased exopolysaccharide production [88]. WspR activity is controlled by three subsequent events: phosphorylation via the chemosensor WspA upon surface contact, which activates c-di-GMP synthesis [88, 258], followed by oligomerization and cluster formation, which increases enzyme activity [259], and finally, c-di-GMP-dependent feedback inhibition [260]. Contrarily, RocR is an example for a PDE of $P$. aeruginosa, representing the response regulator in the RocSAR signaling system, which is composed of 
a membrane sensor RocS1 and two response regulators RocR and RocA1 [227, 261]. The Roc system regulates biofilm formation and virulence gene expression, i.e. the cup fimbriae gene clusters or type III secretion system genes [261, 262]. Besides WspR and RocR, several other DGCs and PDEs have been reported to play a role in $P$. aeruginosa biofilm formation. In addition to WspR at least four other DGCs, i.e. SadC, RoeA, SiaD, and YfiN/TpbB, control the transition from the planktonic to the biofilm lifestyle [263265], while the two DGCs GcbA and NicD as well as the three PDEs DipA, RbdA and NbdA are involved in dispersal of mature biofilms [266-270]. Currently, more than a dozen c-di-GMP-recognizing effectors have been identified in $P$. aeruginosa with about half of them harbouring a PilZ domain [255]. One of them is the membrane-associated protein Alg44, which is required for alginate production [271]. The transcription factor FleQ activates flagellar gene expression and represses pel, psl and $c d r$ genes upon low levels of c-di-GMP [272]. However, when c-di-GMP levels increase FleQ changes into an activator, even though FleQ lacks a PilZ domain [273]. Notably, c-di-GMP not only binds to DGCs, PDEs, PilZ domains and transcriptional factors, but may also act as a competitive inhibitor for ATP catabolizing enzymes, such as the Flil flagellar ATPase [274].

There is also growing evidence for c-di-GMP signaling in Gram-positive bacteria, predominantly studied in Bacillus subtilis, Clostridium difficile and Listeria monocytogenes [275]. Impact of c-di-GMP on staphylococci is under debate. Although S. aureus and S. epidermidis cannot metabolize c-di-GMP they encode the degenerated GGDEFprotein CdgS, which lacks cyclase activity $[276,277]$. Notably, deletion of $g d p S$ reduces biofilm development in both pathogens, however, whether GdpS senses c-di-GMP is controversial $[276,277]$.

\section{Regulatory small RNAs (sRNAs)}

SRNAs have diverse roles as auxiliary regulators affecting QS in a direct or indirect way. This involves mediating the amount of autoinducer synthesis, integrating different regulation inputs or regulating crosstalk among different network components.

The four Hfq-dependent quorum regulatory RNAs (Qrr1-4) of $V$. cholerae prevent translation of the hapR mRNA by base pairing to the 5 '-untranslated region (UTR) [278]. Along the QS signaling cascade low autoinducer concentrations result in phosphorylated LuxO, which together with the alternative sigma factor $\sigma^{5}$ induces Qrr sRNA expression [279]. The four Qrr sRNAs of $V$. cholerae compensate each other and thus can all fully inhibit HapR [280]. On the other side, Qrrs promote aphA mRNA translation by revealing the ribosome binding site [281]. AphA is not only a transcriptional activator of virulence, but also of biofilm formation by promoting expression of the biofilm regulator VpsT [282]. Recently, an RNA-seq study identified the sRNA VqmR to inhibit biofilm formation by translational silencing of the vpsT mRNA [283]. Moreover, the sRNAs CsrB, CsrC and $\mathrm{CsrD}$, which are controlled by the two-component system VarS/A, block activity of the RNA-binding CsrA [284]. The carbon storage regulatory protein CsrA is a major regu- lator for carbon storage, but also impacts biofilm formation and virulence [284, 285]. CsrA can impact the QS cascades by interfering in LuxO-dependent activation of the sRNAs Qrr1-4 resulting in elevated HapR expression as well as stimulation of HapR activity [284, 286].

In $P$. aeruginosa the CsrA-homolog RsmA (regulator of stationary phase metabolites) is controlled by four sRNAs, i.e. RsmZ, RsmY, RsmW and RsmV [287-290]. The primary sRNAs that sequester RsmA are RsmZ and RsmY, while RsmV and RsmW seem to play accessory roles. RsmA acts as a negative post-transcriptional regulator of biofilm formation blocking Psl exopolysaccharide production and other QS-controlled genes [291, 292]. The two sRNAs RsmZ and RsmY are positively controlled by the LadS-RetSGacS/A signal transduction pathway [291, 293, 294]. Expression of RsmV and especially RsmW rises with increasing cell density [287, 290]. Recently, the RNA-binding protein RsmF, a structurally distinct homologue of RsmA, has also shown to bind sRNAs and thereby reduce biofilm formation capacity $[289,295]$. Another $P$. aeruginosa sRNA negatively regulating biofilm formation is $\mathrm{CrcZ}$, which is upregulated under anaerobic conditions [296]. Originally identified as a decoy that sequesters Hfq during relief of carbon catabolite repression, the exact physiological role of $\mathrm{CrCZ}$ along biofilm formation remains to be elucidated [297]. Moreover, PQS synthesis in P. aeruginosa is stimulated by the sRNA PhrS [298]. PhrS is highly expressed under oxygen limiting conditions as it is positively controlled by the oxygen-responsive regulator ANR [298].

More than 250 sRNAs have been discovered in S. aureus, but functional studies are still lacking for most of them [299]. An extensively studied regulatory RNA is the 514 nucleotide-long RNAIII representing the multifunctional effector of the Agr QS cascade. Interestingly, RNAIll contains a small open reading frame encoding the $\delta$-hemolysin, but also functions as a regulatory sRNA controlling translation initiation and mRNA stability of a number of $S$. aureus transcripts via base-pairing with their $5^{\prime}$-UTR [224, 226]. Unlike many other sRNAs, RNAIII is Hfq-independent, but requires the RNA-binding protein strand-specific endoribonuclease III (RNase III), which degrades several RNAIIItargeted mRNAs [300]. Besides others, RNAIII negatively regulates translation of the transcription factor Rot and the cell surface protein $A$, while translation of the transcription factor MgrA is promoted [301]. Overall, this reduces biofilm formation as the surface protein Spa acts as adhesin, Rot represses several secreted proteases capable of biofilm matrix degradation, and MgrA downregulates expression of the phenol-soluble modulins important along biofilm formation [302, 303]. The icaR mRNA, encoding the transcriptional repressor of PIA synthesis, exhibits a negative feedback regulation as the $3^{\prime}$-UTR interferes with translation of its own RNA [304]. Moreover, the 5'-UTR of sarA contains the sRNA teg49, which facilitates expression of the transcriptional regulator SarA and thereby promotes biofilm formation [305]. 
Transcriptional regulators, two-component systems, and alternative sigma factors

VpsR and VpsT represent the two major positive regulators of biofilm formation in $V$. cholerae, which control expression of the VPS exopolysaccharide and biofilm matrix proteins [240]. Complexity of the regulatory network is given by their overlapping, but not identical function and by the fact that they activate each other's expression [251]. While VpsT activity is independent of phosphorylation, VpsR activation requires phosphorylation on the D59 amino acid residue [81]. However, a sensor histidine kinase catalyzing the phosphotransfer has not yet been identified. VpsR and VpsT are repressed by the QS regulator HapR, while VpsT is under positive control of AphA and stringent response in a RpoS-dependent manner [240, 282, 306]. In addition to the QS system, activity of HapR is also modulated by the twocomponent system VarS/VarA via the sRNAs csrB-D and their binding protein CsrA (see above) [284, 286]. The signal sensed by VarS remains to be elucidated. Moreover, HapR expression is activated by the transcriptional regulator VqmA at low cell density and by the alternative sigma factor RpoS [203, 204].

In $P$. aeruginosa two-component systems aid in a stagespecific control of biofilm formation, e.g. the GacA/S, $\mathrm{BfiR} / \mathrm{S}, \mathrm{BfmR} / \mathrm{S}$, and MifR/S regulatory networks [307]. The GacA/S two-component system controls the sRNAs RsmZ and RsmY, which act as antagonists of RsmA modulating Psl exopolysaccharide production (see sRNA section for details) [294, 308]. Phosphorylation of GacA via GacS is inversely regulated by RetS and LadS. While RetS interferes in GacS autophosphorylation by formation of RetS/GacS heterodimers, LadS stimulates GacA phosphorylation [294, 309]. The BfiR/S, BfmR/S, and MifR/S systems regulate defined steps along the $P$. aeruginosa biofilm formation. $\mathrm{BfiR} / \mathrm{S}$ is involved in the transition into the biofilm stage and initial attachment, BfmR/S controls biofilm maturation after irreversible attachment, and MifR/S is rather relevant for subsequent microcolony formation [307]. The alternative sigma factor AlgU (also known as RpoE) is responsible for transcription of the alginate biosynthetic operon and a key factor along the conversion from the non-mucoid to the mucoid phenotype in CF [310]. This conversion is frequently based on spontaneous mutations in mucA, encoding the anti-sigma factor of AlgU [311]. This results in increased activity of AlgU and consequently alginate overproduction [311, 312].

Most S. aureus strains encode 16 different twocomponent systems [313]. Among them, the oxygendependent system SrAB, has been shown to regulate pathogenicity, promoting PIA biosynthesis upon activation of icaADBC transcription via IcaR and, thus facilitating biofilm formation [314, 315]. A major transcriptional regulator relevant for biofilm formation is the staphylococcal accessory regulator SarA [316]. SarA positively regulates the expression of Agr and RNAIII, but also regulates several genes involved in biofilm formation directly [317]. Representative examples include the fibronectin-binding proteins FnbPA and FnBPB as well as the cell wall adhesin Bap, which are activated, while nucleases and proteases are repressed [316, 318]. The stress-induced alternative sigma factor SigB is also crucial for biofilm formation in $S$. aureus and S. epidermidis $[253,319]$. In S. aureus sigB mutants are impaired for in vitro biofilm formation, most likely due to an unleashed activation of the Agr system and massive upregulation of proteases and nucleases [129, 188, 190, 253]. Similarly, $\operatorname{sig} B$ mutants show reduced biofilm formation in S. epidermidis, which correlates with lower PIA production $[319,320]$.

\section{THERAPEUTICAL INTERVENTION STRATEGIES AGAINST BACTERIAL BIOFILMS}

As discussed above, biofilms are a troublesome barrier to components of the host immune system as well as many treatments conventionally used to solve microbial infections, especially antibiotics. Due to the medical importance of bacterial biofilms, effective therapeutical strategies targeting biofilms are highly relevant for clinical applications. Indeed, several potential clinical interventions for treatment of bacterial biofilms associated with infections have been recently suggested.

Despite having lower effectiveness, conventional antibiotics can be used to treat biofilms to some extent. However, antibiotic therapy needs to be evaluated case-bycase, since the efficacy varies depending on the bacterial species, location of the infection, and mode of delivery. Otherwise, ineffective use of antibiotics increases the risk of antibiotic resistance [321]. Antibiotic lock therapy, a technique based on coating the lumen of catheters with a small volume of a concentrated antimicrobial cocktail, has been used for many years as a preventive measure against bacterial adhesion to catheter surfaces [322]. In the case of CF-associated chronic $P$. aeruginosa lung infection, the use of aerosolized antibiotic mixtures has positive results when compared to oral or intravenous administration, and many commercial aerosol formulations are available [323]. Furthermore, novel compounds such as antimicrobial peptides and peptide nucleic acids are highly effective at preventing biofilm formation and breaking down mature biofilms, thus showing great promise for future human use [324, 325]

Among the identified regulatory pathways involved in biofilm formation, QS is not only the most important regulatory circuit, but also found in many bacterial species. Consequently, disruption of QS, named quorum quenching, can be a promising medical application to treat biofilmassociated infections. Using different chemicals, quorum quenching can be performed at several levels, namely preventing bacterial adhesion, inhibiting biofilm maturation, or causing mature biofilms to disintegrate. Although quorum quenching does not kill bacteria, it renders them more sensitive to conventional therapies and could be used in combination with antibiotics, for instance. Several approaches of this kind have been reported successful in $P$. aeruginosa and S. aureus biofilms [326]. As highlighted throughout this review, c-di-GMP is an important signaling molecule promoting biofilm formation in many bacteria [327]. Inhibitors of c-di-GMP-synthesizing diguanylate cyclases have recently been discovered and already shown 
to effectively inhibit biofilm synthesis in $P$. aeruginosa and A. baumanii [328].

Nowadays the chemical composition of the biofilm matrix is known for most pathogenic microbes, and so, a viable option would be to disperse biofilm-enclosed bacterial cells by degrading the matrix. One major component of many bacterial biofilms is eDNA, and bacteria produce their own nucleases to digest the eDNA for, among other ends, dispersing the biofilm matrix depending on environmental conditions [329]. Many strategies were employed in previous studies, such as artificial upregulation of bacterial nucleases and treatment of biofilms with exogenous DNase, which were successful in dispersing biofilms [329]. As such, nucleases have potential to become therapeutic agents in a similar way to quorum quenching agents, destroying the protective matrix, and rendering bacteria sensitive to other treatments. Clinical $P$. aeruginosa isolates tend to produce high levels of the biofilm matrix component alginate, an indicator for serious disease prognoses in CF patients [312]. Alginate lyases, which degrade alginate polymers, have been extracted and purified from several bacterial species and successfully used in combination with antibiotics to treat clinical $P$. aeruginosa biofilms [330]. Moreover, many members of the Enterobacteriaceae family produce extracellular amyloid fibers, which are detrimental for their ability to adhere to surfaces and to generate and maintain biofilms. In this context, specific bioactive compounds have been identified, which inhibit formation of these fibers, and which effectively prevent biofilm formation and destabilize mature biofilms in pathogenic E. coli [331].

The impact of LecA and LecB on P. aeruginosa virulence and biofilm formation initiated therapeutical strategies based on compounds specifically inhibiting binding capacities of these lectins [156]. Beneficial effects were observed upon co-administration of lectin-inhibiting carbohydrates in a lung infection animal model, highlighted by reduced lung injury and mortality compared to the control group [156].

Weak acids, namely the acetic acid present in vinegar, have been used empirically as disinfectants for thousands of years, but research into their antibacterial effects only started to flourish in the last century [332]. Presently, in vitro and in vivo assays have proven that weak organic acids, as well as derivative drugs and salts, are extremely effective in penetrating the biofilm matrix and killing biofilm-implanted $P$. aeruginosa and $S$. aureus, as well as planktonic cells [333]. Especially, weak acids show strong potential as a topical treatment for wound biofilms [333].

Use of bacteriophages is considered an advantageous alternative to antibiotics in the treatment of antibioticresistant infections [334]. The same strategy could be applied to biofilm-associated infections, since it is known that some phages possess hydrolytic enzymes on their surface, enabling them to invade the biofilm matrix and infect bacteria inside biofilms [335]. For example, degradation of the alginate polymer has been reported for $P$. aeruginosa phages [336]. Furthermore, lysogenic phages can be genetically engineered, providing useful and versatile tools for not only inducing lysis in biofilm-rooted cells, but also modulating their behavior in many other ways [337]. Phage therapy has proven effective in ameliorating $P$. aeruginosa biofilm infections in chronic otitis patients and in a murine chronic lung infection model [338, 339]. Bacteriophage treatment combined with prior debridement of biofilm material significantly improved wound healing in a chronic S. aureus wound infection model [340]. However, there are still limitations to the usage of phages such as the risk of development of bacterial resistance against phages, the possibility of undesired horizontal gene transfer via lysogenic phages to share virulence-related genetic elements across the biofilm community, and phage immunogenicity resulting in generation of neutralizing antibodies by the human host, which could translate into inflammatory side effects [337].

\section{CONCLUDING REMARKS}

Bacterial biofilms pose a great challenge to our health care system as they are involved in various human diseases and exhibit high antimicrobial resistance. Clinical relevance ranges from biofilms formed on diverse body surfaces, medical devices-related biofilms, and environmental biofilms of facultative pathogens, which act as a reservoir for infections. Given the global burden of biofilm-associated infections, therapeutic intervention strategies targeting biofilms are desperately needed. Using selected model organisms, we have made substantial progress to understand biofilm development, composition and regulation. This revealed common principles as well as species-specific differences, which resulted in new therapeutic strategies to promote biofilm dispersal or even combat initial biofilm formation. However, future initiatives need to translate in vitro results of promising therapeutic agents to in vivo systems and clinical trials. This might be hampered by increasing evidence that in vitro biofilm formation under laboratory settings not always reflects the in vivo situation. Relevant differences between in vitro and in vivo biofilm formation include chemical composition of the abiotic surfaces, presence of host-derived factors or interactions with other microbes resulting in multi-species biofilms. It will be a challenging, but necessary task for future research to develop new biofilm models that more closely reflect the in vivo situation.

\section{ACKNOWLEDGMENTS}

Apologies to all scientists studying bacterial biofilms whose work and research could be not mentioned in this review. This work was supported by the Austrian FWF grants P27654 to S.S., P32577 to S.S., W901-B12 (DK Molecular Enzymology) to F.M. and S.S., DOC-50 (docfund "Molecular Metabolism") to J.P.P and S.S., by the DocAcademy Graz to A.S. and S.S., by BioTechMed Graz to S.S. as well as by the Land Steiermark and City of Graz. "A.S. and F.M. contributed equally to this work.

\section{CONFLICT OF INTEREST}

The authors declare no conflict of interest. 


\section{COPYRIGHT}

(C) 2021 Schulze et al. This is an open-access article released under the terms of the Creative Commons Attribution (CC BY) license, which allows the unrestricted use, distribution, and reproduction in any medium, provided the original author and source are acknowledged.

\section{REFERENCES}

1. Høiby N (2014). A Personal History of Research on Microbial Biofilms and Biofilm Infections. Pathog Dis 70(3): 205-11. doi: 10.1111/2049-632X.12165

2. Jamal M, Ahmad W, Andleeb S, Jalil F, Imran M, Nawaz MA, Hussain T, Ali M, Rafiq M, Kamil MA (2018). Bacterial biofilm and associated infections. J Chin Med Assoc 81(1): 7-11. doi: 10.1016/j.jcma.2017.07.012

3. Tamayo R, Patimalla B, Camilli A (2010). Growth in a biofilm induces a hyperinfectious phenotype in Vibrio cholerae. Infect Immun 78(8): 3560-3569. doi: 10.1128/IAI.00048-10

4. Seper A, Fengler VH, Roier S, Wolinski H, Kohlwein SD, Bishop AL, Camilli A, Reidl J, Schild S (2011). Extracellular nucleases and extracellular DNA play important roles in Vibrio cholerae biofilm formation. Mol Microbiol 82(4): 1015-1037. doi: 10.1111/j.13652958.2011.07867.x

5. Colwell RR, Huq A, Islam MS, Aziz KM, Yunus M, Khan NH, Mahmud A, Sack RB, Nair GB, Chakraborty J, Sack DA, Russek-Cohen E (2003). Reduction of cholera in Bangladeshi villages by simple filtration. Proc Natl Acad Sci U S A 100(3): 1051-1055. doi: 10.1073/pnas.0237386100

6. Al Safadi R, Abu-Ali GS, Sloup RE, Rudrik JT, Waters CM, Eaton KA, Manning SD (2012). Correlation between in vivo biofilm formation and virulence gene expression in Escherichia coli 0104:H4. PLoS One 7(7): e41628. doi: 10.1371/journal.pone.0041628

7. Richter AM, Povolotsky TL, Wieler LH, Hengge R (2014). Cyclic-diGMP signalling and biofilm-related properties of the Shiga toxinproducing 2011 German outbreak Escherichia coli O104:H4. EMBO Mol Med 6(12): 1622-1637. doi: 10.15252/emmm.201404309

8. Proctor CR, Reimann M, Vriens B, Hammes F (2018). Biofilms in shower hoses. Water Res 131: 274-286. doi: 10.1016/j.watres.2017.12.027

9. Darouiche RO (2004). Treatment of infections associated with surgical implants. N Engl J Med 350(14): 1422-1429. doi: 10.1056/NEJMra035415

10. Donlan RM (2001). Biofilms and device-associated infections. Emerg Infect Dis 7(2): 277-281. doi: 10.3201/eid0702.010226

11. Srivastava A, Chandra N, Kumar S (2019). The Role of Biofilms in Medical Devices and Implants. In: Kumar S, Chandra N, Singh L, Hashmi MZ, Varma A, editors. Biofilms in Human Diseases: Treatment and Control. Springer International Publishing, Cham; pp 151-165. doi: 10.1007/978-3-030-30757-8

12. Raad I, Costerton W, Sabharwal U, Sacilowski M, Anaissie E, Bodey GP (1993). Ultrastructural analysis of indwelling vascular catheters: a quantitative relationship between luminal colonization and duration of placement. J Infect Dis 168(2): 400-407. doi: 10.1093/infdis/168.2.400

13. Niveditha S, Pramodhini S, Umadevi S, Kumar S, Stephen S (2012). The Isolation and the Biofilm Formation of Uropathogens in the Patients with Catheter Associated Urinary Tract Infections (UTIs). J Clin Diagn Res 6(9): 1478-1482. doi: 10.7860/jcdr/2012/4367.2537
Please cite this article as: Adina Schulze, Fabian Mitterer, Joao P. Pombo and Stefan Schild (2021). Biofilms by bacterial human pathogens: Clinical relevance - development, composition and regulation - therapeutical strategies. Microbial Cell 8(2): 28-56. doi: $10.15698 / \mathrm{mic} 2021.02 .741$

14. Bauer T, Torres A, Ferrer R, Heyer C, Schultze-Werninghaus G Rasche K (2002). Biofilm formation in endotracheal tubes. Association between pneumonia and the persistence of pathogens. Monaldi Arch Chest Dis 57(1): 84-87. PMID: 12174708

15. Craven DE, Hjalmarson KI (2010). Ventilator-associated tracheobronchitis and pneumonia: thinking outside the box. Clin Infect Dis 51 Suppl 1(S59-66). doi: 10.1086/653051

16. Foreman A, Wormald PJ (2010). Different biofilms, different disease? A clinical outcomes study. Laryngoscope 120(8): 1701-1706. doi: 10.1002/lary.21024

17. Hadley JA (2000). Rhinosinusitis. An overview of current management measures in acute and chronic infection. Postgrad Med 108(7 Suppl Contemporaty): 30-36. doi: 10.3810/pgm.12.2000.suppl10.54

18. Kinnari TJ, Lampikoski H, Hyyrynen T, Aarnisalo AA (2012). Bacterial biofilm associated with chronic laryngitis. Arch Otolaryngol Head Neck Surg 138(5): 467-470. doi: 10.1001/archoto.2012.637

19. Crabbé A, De Boever $P$, Van Houdt R, Moors H, Mergeay M, Cornelis $P$ (2008). Use of the rotating wall vessel technology to study the effect of shear stress on growth behaviour of Pseudomonas aeruginosa PA01. Environ Microbiol 10(8): 2098-2110. doi: 10.1111/j.14622920.2008.01631.x

20. Lyczak JB, Cannon CL, Pier GB (2002). Lung infections associated with cystic fibrosis. Clin Microbiol Rev 15(2): 194-222. doi: 10.1128/cmr.15.2.194-222.2002

21. Cole SJ, Records AR, Orr MW, Linden SB, Lee VT (2014). Catheterassociated urinary tract infection by Pseudomonas aeruginosa is mediated by exopolysaccharide-independent biofilms. Infect Immun 82(5): 2048-2058. doi: 10.1128/IAI.01652-14

22. Tielen $\mathrm{P}$, Rosin N, Meyer AK, Dohnt K, Haddad I, Jansch L, Klein J, Narten $M$, Pommerenke C, Scheer $M$, Schobert M, Schomburg D, Thielen B, Jahn D (2013). Regulatory and metabolic networks for the adaptation of Pseudomonas aeruginosa biofilms to urinary tract-like conditions. PLoS One 8(8): e71845. doi 10.1371/journal. pone.0071845

23. Mulcahy LR, Isabella VM, Lewis K (2014). Pseudomonas aeruginosa biofilms in disease. Microb Ecol 68(1): 1-12. doi: 10.1007/s00248-0130297-x

24. Tiddens HA (2002). Detecting early structural lung damage in cystic fibrosis. Pediatr Pulmonol 34(3): 228-231. doi: 10.1002/ppul.10134

25. Tseng BS, Zhang W, Harrison JJ, Quach TP, Song JL, Penterman J, Singh PK, Chopp DL, Packman AI, Parsek MR (2013). The extracellular matrix protects Pseudomonas aeruginosa biofilms by limiting the penetration of tobramycin. Environ Microbiol 15(10): 2865-2878. doi: 10.1111/1462-2920.12155

26. Candido Cacador N, Paulino da Costa Capizzani C, Gomes Monteiro Marin Torres LA, Galetti R, Ciofu O, da Costa Darini AL, Hoiby N (2018). Adaptation of Pseudomonas aeruginosa to the chronic phenotype by mutations in the algTmucABD operon in isolates from Brazilian cystic fibrosis patients. PLoS One 13(11): e0208013. doi: 10.1371/journal.pone.0208013 
27. Høiby N, Ciofu O, Bjarnsholt T (2010). Pseudomonas aeruginosa biofilms in cystic fibrosis. Future Microbiol 5(11): 1663-1674. doi: 10.2217/fmb.10.125

28. Palange $P$, Simonds AK (2013). ERS Handbook of Respiratory Medicine. European Respiratory Society. doi: 10.1183/9781849840415hbaO2

29. Nirwati H, Sinanjung K, Fahrunissa F, Wijaya F, Napitupulu S, Hati VP, Hakim MS, Meliala A, Aman AT, Nuryastuti T (2019). Biofilm formation and antibiotic resistance of Klebsiella pneumoniae isolated from clinical samples in a tertiary care hospital, Klaten, Indonesia. BMC Proc 13(Suppl 11): 20. doi: 10.1186/s12919-019-0176-7

30. Yousefi M, Pourmand MR, Fallah F, Hashemi A, Mashhadi R, Nazari-Alam A (2016). Characterization of Staphylococcus aureus Biofilm Formation in Urinary Tract Infection. Iran J Public Health 45(4): 485493. PMID: 27252918

31. Karigoudar RM, Karigoudar MH, Wavare SM, Mangalgi SS (2019). Detection of biofilm among uropathogenic Escherichia coli and its correlation with antibiotic resistance pattern. J Lab Physicians 11(1): 17-22. doi: 10.4103/JLP.JLP_98_18

32. Madersbacher S, Thalhammer F, Marberger M (2000). Pathogenesis and management of recurrent urinary tract infection in women. Curr Opin Urol 10(1): 29-33. doi: 10.1097/00042307-20000100000008

33. Bartoletti R, Cai T, Nesi G, Albanese S, Meacci F, Mazzoli S, Naber K (2014). The impact of biofilm-producing bacteria on chronic bacterial prostatitis treatment: results from a longitudinal cohort study. World J Urol 32(3): 737-742. doi: 10.1007/s00345-013-1145-9

34. Dewhirst FE, Chen T, Izard J, Paster BJ, Tanner AC, Yu WH, Lakshmanan A, Wade WG (2010). The human oral microbiome. J Bacteriol 192(19): 5002-5017. doi: 10.1128/jb.00542-10

35. Larsen T, Fiehn NE (2017). Dental biofilm infections - an update. APMIS 125(4): 376-384. doi: 10.1111/apm.12688

36. Overman PR (2000). Biofilm: a new view of plaque. J Contemp Dent Pract 1(3): 18-29. doi: 10.5005/jcdp-1-3-37

37. Balakrishnan M, Simmonds RS, Tagg JR (2000). Dental caries is a preventable infectious disease. Aust Dent J 45(4): 235-245. doi: 10.1111/j.1834-7819.2000.tb00257.x

38. Forssten SD, Björklund M, Ouwehand AC (2010). Streptococcus mutans, caries and simulation models. Nutrients 2(3): 290-298. doi: $10.3390 /$ nu2030290

39. Marsh PD, Martin MV, Lewis MAO, Williams D (2009). Oral Microbiology $5^{\text {th }}$ edition. Elsevier, Amsterdam.

40. Lamont RJ, Jenkinson HF (1998). Life below the gum line: pathogenic mechanisms of Porphyromonas gingivalis. Microbiol Mol Biol Rev 62(4): 1244-1263. doi: 0.1128/MMBR.62.4.1244-1263.1998

41. Dubey S, Dubey S, Gupta A, Sharma V (2019). Biofilm-Mediated Dental Diseases. In: Kumar S, Chandra N, Singh L, Hashmi MZ, Varma A, editors. Biofilms in Human Diseases: Treatment and Control. Springer International Publishing, Cham; pp 91-116. doi: 10.1007/978-3-030-30757-8.

42. Brown LM (2000). Helicobacter pylori: epidemiology and routes of transmission. Epidemiol Rev 22(2): 283-297. doi: 10.1093/oxfordjournals.epirev.a018040

43. Carron MA, Tran VR, Sugawa C, Coticchia JM (2006). Identification of Helicobacter pylori biofilms in human gastric mucosa. J Gastrointest Surg 10(5): 712-717. doi: 10.1016/j.gassur.2005.10.019

44. Mobley HL, Cortesia MJ, Rosenthal LE, Jones BD (1988). Characterization of urease from Campylobacter pylori. J Clin Microbiol 26(5): 831-836. doi: 10.1128/jcm.26.5.831-836.1988
45. Coticchia JM, Sugawa C, Tran VR, Gurrola J, Kowalski E, Carron MA (2006). Presence and density of Helicobacter pylori biofilms in human gastric mucosa in patients with peptic ulcer disease. J Gastrointest Surg 10(6): 883-889. doi: 10.1016/j.gassur.2005.12.009

46. Cammarota G, Branca G, Ardito F, Sanguinetti M, laniro G, Cianci R, Torelli R, Masala G, Gasbarrini A, Fadda G, Landolfi R, Gasbarrini G (2010). Biofilm demolition and antibiotic treatment to eradicate resistant Helicobacter pylori: a clinical trial. Clin Gastroenterol Hepatol 8(9): 817-820.e813. doi: 10.1016/j.cgh.2010.05.006

47. Macfarlane S (2008). Microbial biofilm communities in the gastrointestinal tract. J Clin Gastroenterol 42 (Suppl 3 Pt 1): S142-143. doi: 10.1097/MCG.0b013e31816207df

48. Swidsinski A, Weber J, Loening-Baucke V, Hale LP, Lochs H (2005). Spatial organization and composition of the mucosal flora in patients with inflammatory bowel disease. J Clin Microbiol 43(7): 3380-3389. doi: $10.1128 / \mathrm{jcm} \cdot 43.7 .3380-3389.2005$

49. Horie H, Kanazawa K, Okada M, Narushima S, Itoh K, Terada A (1999). Effects of intestinal bacteria on the development of colonic neoplasm: an experimental study. Eur J Cancer Prev 8(3): 237-245. doi: 10.1097/00008469-199906000-00012

50. von Rosenvinge EC, O'May GA, Macfarlane S, Macfarlane GT, Shirtliff ME (2013). Microbial biofilms and gastrointestinal diseases. Pathog Dis 67(1): 25-38. doi: 10.1111/2049-632X.12020

51. Alhagamhmad MH, Day AS, Lemberg DA, Leach ST (2016). An overview of the bacterial contribution to Crohn disease pathogenesis. J Med Microbiol 65(10): 1049-1059. doi: 10.1099/jmm.0.000331

52. Srivastava A, Gupta J, Kumar S, Kumar A (2017). Gut biofilm forming bacteria in inflammatory bowel disease. Microb Pathog 112: 5-14. doi: 10.1016/j.micpath.2017.09.041

53. Singh AKea (2019). Biofilm-Mediated Skin Infections. In: Sunil Kumar NC, Leena Singh, Muhammad Zaffar Hashmi, Ajit Varma, editor Biofilms in Human Diseases: Treatment and Control. Springer International Publishing; pp. 215-231. doi: 10.1007/978-3-030-30757-8.

54. Brandwein M, Steinberg D, Meshner S (2016). Microbial biofilms and the human skin microbiome. NPJ Biofilms Microbiomes 2(1): 3 doi: 10.1038/s41522-016-0004-z

55. Gjødsbø| K, Christensen JJ, Karlsmark T, Jørgensen B, Klein BM, Krogfelt KA (2006). Multiple bacterial species reside in chronic wounds: a longitudinal study. Int Wound J 3(3): 225-231. doi: 10.1111/j.1742-481X.2006.00159.x

56. Bowling FL, Jude EB, Boulton AJ (2009). MRSA and diabetic foot wounds: contaminating or infecting organisms? Curr Diab Rep 9(6): 440-444. doi: 10.1007/s11892-009-0072-z

57. McLaughlin RA, Hoogewerf AJ (2006). Interleukin-1beta-induced growth enhancement of Staphylococcus aureus occurs in biofilm but not planktonic cultures. Microb Pathog 41(2-3): 67-79. doi: 10.1016/j.micpath.2006.04.005

58. Bjarnsholt $T$ (2013). The role of bacterial biofilms in chronic infections. APMIS Suppl 136): 1-51. doi: 10.1111/apm.12099

59. DeLeon S, Clinton A, Fowler H, Everett J, Horswill AR, Rumbaugh KP (2014). Synergistic interactions of Pseudomonas aeruginosa and Staphylococcus aureus in an in vitro wound model. Infect Immun 82(11): 4718-4728. doi: 10.1128/IAI.02198-14

60. McGinley K, Webster G, Ruggieri M, Leyden J (1980). Regional variations in density of cutaneous propionibacteria: correlation of Propionibacterium acnes populations with sebaceous secretion. J Clin Microbiol 12(5): 672-675. doi: 10.1128/JCM.12.5.672-675.1980

61. Coenye T, Peeters E, Nelis HJ (2007). Biofilm formation by Propionibacterium acnes is associated with increased resistance to antimicro- 
bial agents and increased production of putative virulence factors. Res Microbiol 158(4): 386-392. doi: 10.1016/j.resmic.2007.02.001

62. Holmberg A, Lood R, Mörgelin M, Söderquist B, Holst E, Collin M, Christensson B, Rasmussen M (2009). Biofilm formation by Propionibacterium acnes is a characteristic of invasive isolates. Clin Microbiol Infect 15(8): 787-795. doi: 10.1111/j.1469-0691.2009.02747.x

63. Kuehnast T, Cakar F, Weinhäupl T, Pilz A, Selak S, Schmidt MA, Rüter C, Schild S (2018). Comparative analyses of biofilm formation among different Cutibacterium acnes isolates. Int J Med Microbiol 308(8): 1027-1035. doi: 10.1016/j.ijmm.2018.09.005

64. Yeşilkaya A, Azap OK, Pirat B, Gültekin B, Arslan H (2012). A Rare Cause of Endocarditis: Streptococcus pyogenes. Balkan Med J 29(3): 331-333. doi: 10.5152/balkanmedj.2012.053

65. Kokare C, Chakraborty S, Khopade A, Mahadik KR (2009). Biofilm: Importance and applications. Indian J Biotechnol 8:159e68. Available at: http://hdl.handle.net/123456789/3883

66. Lew DP, Waldvogel FA (2004). Osteomyelitis. Lancet 364(9431): 369-379. doi: 10.1016/s0140-6736(04)16727-5

67. Ciampolini J, Harding KG (2000). Pathophysiology of chronic bacterial osteomyelitis. Why do antibiotics fail so often? Postgrad Med J 76(898): 479-483. doi: 10.1136/pmj.76.898.479

68. Bakaletz LO (2007). Bacterial biofilms in otitis media: evidence and relevance. Pediatr Infect Dis J 26(10 Suppl): S17-19. doi: 10.1097/INF.0b013e318154b273

69. Puig C, Domenech A, Garmendia J, Langereis JD, Mayer P, Calatayud L, Liñares J, Ardanuy C, Marti S (2014). Increased biofilm formation by nontypeable Haemophilus influenzae isolates from patients with invasive disease or otitis media versus strains recovered from cases of respiratory infections. Appl Environ Microbiol 80(22): 7088-7095. doi: 10.1128/aem.02544-14

70. Rodríguez-Baño J, Martí S, Soto $S$, Fernández-Cuenca F, Cisneros JM, Pachón J, Pascual A, Martínez-Martínez L, McQueary C, Actis LA, Vila J (2008). Biofilm formation in Acinetobacter baumannii: associated features and clinical implications. Clin Microbiol Infect 14(3): 276278. doi: 10.1111/j.1469-0691.2007.01916.x

71. Yi K, Rasmussen AW, Gudlavalleti SK, Stephens DS, Stojiljkovic I (2004). Biofilm formation by Neisseria meningitidis. Infect Immun 72(10): 6132-6138. doi: 10.1128/iai.72.10.6132-6138.2004

72. Conner JG, Teschler JK, Jones CJ, Yildiz FH (2016). Staying Alive: Vibrio cholerae's Cycle of Environmental Survival, Transmission, and Dissemination. Microbiol Spectr 4(2). doi: 10.1128/microbiolspec.VMBF-0015-2015

73. Maurice NM, Bedi B, Sadikot RT (2018). Pseudomonas aeruginosa Biofilms: Host Response and Clinical Implications in Lung Infections. Am J Respir Cell Mol Biol 58(4): 428-439. doi: 10.1165/rcmb.20170321TR

74. Otto M (2018). Staphylococcal Biofilms. Microbiol Spectr 6(4). doi: 10.1128/microbiolspec.GPP3-0023-2018

75. Paharik AE, Horswill AR (2016). The Staphylococcal Biofilm: Adhesins, Regulation, and Host Response. Microbiol Spectr 4(2). doi: 10.1128/microbiolspec.VMBF-0022-2015

76. O'Toole GA, Kolter R (1998). Flagellar and twitching motility are necessary for Pseudomonas aeruginosa biofilm development. Mol Microbiol 30(2): 295-304. doi: 10.1046/j.1365-2958.1998.01062.x

77. Watnick PI, Kolter R (1999). Steps in the development of a Vibrio cholerae El Tor biofilm. Mol Microbiol 34(3): 586-595. doi: 10.1046/j.1365-2958.1999.01624.x
78. Kojima S, Yamamoto K, Kawagishi I, Homma M (1999). The polar flagellar motor of Vibrio cholerae is driven by an $\mathrm{Na}+$ motive force. $J$ Bacteriol 181(6): 1927-1930. doi: 10.1128/JB.181.6.1927-1930.1999

79. Watnick PI, Lauriano CM, Klose KE, Croal L, Kolter R (2001). The absence of a flagellum leads to altered colony morphology, biofilm development and virulence in Vibrio cholerae 0139. Mol Microbiol 39(2): 223-235. doi: 10.1046/j.1365-2958.2001.02195.x

80. Utada AS, Bennett RR, Fong JCN, Gibiansky ML, Yildiz FH, Golestanian R, Wong GCL (2014). Vibrio cholerae use pili and flagella synergistically to effect motility switching and conditional surface attachment. Nat Commun 5: 4913. doi: 10.1038/ncomms5913

81. Lauriano CM, Ghosh C, Correa NE, Klose KE (2004). The sodiumdriven flagellar motor controls exopolysaccharide expression in Vibrio cholerae. J Bacteriol 186(15): 4864-4874. doi: 10.1128/JB.186.15.4864-4874.2004

82. Huq A, Small EB, West PA, Huq MI, Rahman R, Colwell RR (1983). Ecological relationships between Vibrio cholerae and planktonic crustacean copepods. Appl Environ Microbiol 45(1): 275-283. doi: 10.1128/AEM.45.1.275-283.1983

83. Chiavelli DA, Marsh JW, Taylor RK (2001). The mannose-sensitive hemagglutinin of Vibrio cholerae promotes adherence to zooplankton. Appl Environ Microbiol 67(7): 3220-3225. doi 10.1128/AEM.67.7.3220-3225.2001

84. Kitts G, Giglio KM, Zamorano-Sanchez D, Park JH, Townsley L, Cooley RB, Wucher BR, Klose KE, Nadell CD, Yildiz FH, Sondermann H (2019). A Conserved Regulatory Circuit Controls Large Adhesins in Vibrio cholerae. mBio 10(6): e02822-19. doi: 10.1128/mBio.02822-19

85. Sauer K, Camper AK, Ehrlich GD, Costerton JW, Davies DG (2002). Pseudomonas aeruginosa displays multiple phenotypes during development as a biofilm. J Bacteriol 184(4): 1140-1154. doi: 10.1128/jb.184.4.1140-1154.2002

86. Gibiansky ML, Conrad JC, Jin F, Gordon VD, Motto DA, Mathewson MA, Stopka WG, Zelasko DC, Shrout JD, Wong GC (2010). Bacteria use type IV pili to walk upright and detach from surfaces. Science 330(6001): 197. doi: 10.1126/science.1194238

87. Klausen M, Aaes-Jorgensen A, Molin S, Tolker-Nielsen T (2003). Involvement of bacterial migration in the development of complex multicellular structures in Pseudomonas aeruginosa biofilms. Mol Microbiol 50(1): 61-68. doi: 10.1046/j.1365-2958.2003.03677.x

88. Hickman JW, Tifrea DF, Harwood CS (2005). A chemosensory system that regulates biofilm formation through modulation of cyclic diguanylate levels. Proc Natl Acad Sci U S A 102(40): 14422-14427. doi: 10.1073/pnas.0507170102

89. Borlee BR, Goldman AD, Murakami K, Samudrala R, Wozniak DJ, Parsek MR (2010). Pseudomonas aeruginosa uses a cyclic-di-GMPregulated adhesin to reinforce the biofilm extracellular matrix. Mol Microbiol 75(4): 827-842. doi: 10.1111/j.1365-2958.2009.06991.x

90. O'Connor JR, Kuwada NJ, Huangyutitham V, Wiggins PA, Harwood CS (2012). Surface sensing and lateral subcellular localization of WspA, the receptor in a chemosensory-like system leading to c-di-GMP production. Mol Microbiol 86(3): 720-729. doi: 10.1111/mmi.12013

91. Vallet I, Olson JW, Lory S, Lazdunski A, Filloux A (2001). The chaperone/usher pathways of Pseudomonas aeruginosa: identification of fimbrial gene clusters (cup) and their involvement in biofilm formation. Proc Natl Acad Sci U S A 98(12): 6911-6916. doi: 10.1073/pnas.111551898

92. Heilmann C (2011). Adhesion mechanisms of staphylococci. Adv Exp Med Biol 715: 105-123. doi: 10.1007/978-94-007-0940-9_7

93. Bose JL, Lehman MK, Fey PD, Bayles KW (2012). Contribution of the Staphylococcus aureus Atl AM and GL murein hydrolase activities 
in cell division, autolysis, and biofilm formation. PLoS One 7(7): e42244. doi: 10.1371/journal.pone.0042244

94. Heilmann C, Hussain M, Peters G, Gotz F (1997). Evidence for autolysin-mediated primary attachment of Staphylococcus epidermidis to a polystyrene surface. Mol Microbiol 24(5): 1013-1024. doi: 10.1046/j.1365-2958.1997.4101774.x

95. Clarke SR, Foster SJ (2006). Surface adhesins of Staphylococcus aureus. Adv Microb Physiol 51: 187-224. doi: 10.1016/S00652911(06)51004-5

96. Schneewind O, Mihaylova-Petkov D, Model P (1993). Cell wall sorting signals in surface proteins of gram-positive bacteria. EMBO J 12(12): 4803-4811. doi: 10.1002/j.1460-2075.1993.tb06169.x

97. Cascioferro S, Totsika M, Schillaci D (2014). Sortase A: an ideal target for anti-virulence drug development. Microb Pathog 77: 105112. doi: 10.1016/j.micpath.2014.10.007

98. Chavakis T, Wiechmann K, Preissner KT, Herrmann M (2005). Staphylococcus aureus interactions with the endothelium: the role of bacterial "secretable expanded repertoire adhesive molecules" (SERAM) in disturbing host defense systems. Thromb Haemost 94(2): 278-285. doi: 10.1160/TH05-05-0306

99. Christner M, Franke GC, Schommer NN, Wendt U, Wegert K, Pehle P, Kroll G, Schulze C, Buck F, Mack D, Aepfelbacher M, Rohde H (2010). The giant extracellular matrix-binding protein of Staphylococcus epidermidis mediates biofilm accumulation and attachment to fibronectin. Mol Microbiol 75(1): 187-207. doi: 10.1111/j.13652958.2009.06981.x

100. Clarke SR, Harris LG, Richards RG, Foster SJ (2002). Analysis of Ebh, a 1.1-megadalton cell wall-associated fibronectin-binding protein of Staphylococcus aureus. Infect Immun 70(12): 6680-6687. doi: 10.1128/iai.70.12.6680-6687.2002

101. Fong JCN, Syed KA, Klose KE, Yildiz FH (2010). Role of Vibrio polysaccharide ( $v p s)$ genes in VPS production, biofilm formation and Vibrio cholerae pathogenesis. Microbiology (Reading) 156(Pt 9): 2757-2769. doi: 10.1099/mic.0.040196-0

102. Moorthy S, Watnick PI (2004). Genetic evidence that the Vibrio cholerae monolayer is a distinct stage in biofilm development. Mol Microbiol 52(2): 573-587. doi: 10.1111/j.1365-2958.2004.04000.x

103. Yildiz F, Fong J, Sadovskaya I, Grard T, Vinogradov E (2014). Structural characterization of the extracellular polysaccharide from Vibrio cholerae 01 El-Tor. PLoS One 9(1): e86751. doi: 10.1371/journal.pone.0086751

104. Berk V, Fong JC, Dempsey GT, Develioglu ON, Zhuang X, Liphardt J, Yildiz FH, Chu S (2012). Molecular architecture and assembly principles of Vibrio cholerae biofilms. Science 337(6091): 236-239. doi: 10.1126/science. 1222981

105. Yildiz FH, Schoolnik GK (1999). Vibrio cholerae O1 El Tor: identification of a gene cluster required for the rugose colony type, exopolysaccharide production, chlorine resistance, and biofilm formation. Proc Natl Acad Sci U S A 96(7): 4028-4033. doi: 10.1073/pnas.96.7.4028

106. Fong JC, Karplus K, Schoolnik GK, Yildiz FH (2006). Identification and characterization of RbmA, a novel protein required for the development of rugose colony morphology and biofilm structure in Vibrio cholerae. J Bacteriol 188(3): 1049-1059. doi: 10.1128/JB.188.3.10491059.2006

107. Fong JC, Yildiz FH (2007). The $r b m B C D E F$ gene cluster modulates development of rugose colony morphology and biofilm formation in Vibrio cholerae. J Bacteriol 189(6): 2319-2330. doi: 10.1128/JB.0156906
108. Ryder C, Byrd M, Wozniak DJ (2007). Role of polysaccharides in Pseudomonas aeruginosa biofilm development. Curr Opin Microbiol 10(6): 644-648. doi: 10.1016/j.mib.2007.09.010

109. Muhammadi, Ahmed N (2007). Genetics of bacterial alginate: alginate genes distribution, organization and biosynthesis in bacteria. Curr Genomics 8(3): 191-202. doi: 10.2174/138920207780833810

110. Leid JG, Willson CJ, Shirtliff ME, Hassett DJ, Parsek MR, Jeffers AK (2005). The exopolysaccharide alginate protects Pseudomonas aeruginosa biofilm bacteria from IFN-gamma-mediated macrophage killing. J Immunol 175(11): 7512-7518. doi: 10.4049/jimmunol.175.11.7512

111. Hoiby N, Bjarnsholt T, Givskov M, Molin S, Ciofu O (2010). Antibiotic resistance of bacterial biofilms. Int J Antimicrob Agents 35(4): 322-332. doi: 10.1016/j.ijantimicag.2009.12.011

112. Wozniak DJ, Wyckoff TJ, Starkey M, Keyser R, Azadi P, O'Toole GA, Parsek MR (2003). Alginate is not a significant component of the extracellular polysaccharide matrix of PA14 and PAO1 Pseudomonas aeruginosa biofilms. Proc Natl Acad Sci U S A 100(13): 7907-7912. doi: 10.1073/pnas.1231792100

113. Stapper AP, Narasimhan G, Ohman DE, Barakat J, Hentzer M, Molin S, Kharazmi A, Hoiby N, Mathee K (2004). Alginate production affects Pseudomonas aeruginosa biofilm development and architecture, but is not essential for biofilm formation. J Med Microbiol 53(Pt 7): 679-690. doi: 10.1099/jmm.0.45539-0

114. Friedman L, Kolter R (2004). Two genetic loci produce distinct carbohydrate-rich structural components of the Pseudomonas aeruginosa biofilm matrix. J Bacteriol 186(14): 4457-4465. doi: 10.1128/JB.186.14.4457-4465.2004

115. Vasseur P, Vallet-Gely I, Soscia C, Genin S, Filloux A (2005). The pel genes of the Pseudomonas aeruginosa PAK strain are involved at early and late stages of biofilm formation. Microbiology (Reading) 151(Pt 3): 985-997. doi: 10.1099/mic.0.27410-0

116. Byrd MS, Sadovskaya I, Vinogradov E, Lu H, Sprinkle AB, Richard son SH, Ma L, Ralston B, Parsek MR, Anderson EM, Lam JS, Wozniak DJ (2009). Genetic and biochemical analyses of the Pseudomonas aeruginosa Psl exopolysaccharide reveal overlapping roles for polysaccharide synthesis enzymes in PsI and LPS production. Mol Microbiol 73(4): 622-638. doi: 10.1111/j.1365-2958.2009.06795.x

117. Ma L, Lu H, Sprinkle A, Parsek MR, Wozniak DJ (2007). Pseudomonas aeruginosa $\mathrm{Psl}$ is a galactose- and mannose-rich exopolysaccharide. J Bacteriol 189(22): 8353-8356. doi: 10.1128/JB.00620-07

118. Wang S, Liu X, Liu H, Zhang L, Guo Y, Yu S, Wozniak DJ, Ma LZ (2015). The exopolysaccharide Psl-eDNA interaction enables the formation of a biofilm skeleton in Pseudomonas aeruginosa. Environ Microbiol Rep 7(2): 330-340. doi: 10.1111/1758-2229.12252

119. Zhao K, Tseng BS, Beckerman B, Jin F, Gibiansky ML, Harrison JJ, Luijten E, Parsek MR, Wong GCL (2013). Psl trails guide exploration and microcolony formation in Pseudomonas aeruginosa biofilms. Nature 497(7449): 388-391. doi: 10.1038/nature12155

120. Jennings LK, Storek KM, Ledvina HE, Coulon C, Marmont LS, Sadovskaya I, Secor PR, Tseng BS, Scian M, Filloux A, Wozniak DJ, Howell $\mathrm{PL}$, Parsek MR (2015). Pel is a cationic exopolysaccharide that crosslinks extracellular DNA in the Pseudomonas aeruginosa biofilm matrix. Proc Natl Acad Sci U S A 112(36): 11353-11358. doi: 10.1073/pnas.1503058112

121. Colvin KM, Gordon VD, Murakami K, Borlee BR, Wozniak DJ, Wong GC, Parsek MR (2011). The pel polysaccharide can serve a structural and protective role in the biofilm matrix of Pseudomonas aeruginosa. PLoS Pathog 7(1): e1001264. doi: 10.1371/journal.ppat.1001264 
122. Mack D, Fischer W, Krokotsch A, Leopold K, Hartmann R, Egge $H$, Laufs $R$ (1996). The intercellular adhesin involved in biofilm accumulation of Staphylococcus epidermidis is a linear beta-1,6-linked glucosaminoglycan: purification and structural analysis. J Bacteriol 178(1): 175-183. doi: 10.1128/jb.178.1.175-183.1996

123. Rupp ME, Ulphani JS, Fey PD, Bartscht K, Mack D (1999). Characterization of the importance of polysaccharide intercellular adhe$\mathrm{sin} /$ hemagglutinin of Staphylococcus epidermidis in the pathogenesis of biomaterial-based infection in a mouse foreign body infection model. Infect Immun 67(5): 2627-2632. doi: 10.1128/IAI.67.5.26272632.1999

124. Heilmann C, Schweitzer O, Gerke C, Vanittanakom N, Mack D, Gotz F (1996). Molecular basis of intercellular adhesion in the biofilmforming Staphylococcus epidermidis. Mol Microbiol 20(5): 1083-1091. doi: 10.1111/j.1365-2958.1996.tb02548.x

125. Gerke C, Kraft A, Sussmuth R, Schweitzer O, Gotz F (1998). Characterization of the $\mathrm{N}$-acetylglucosaminyltransferase activity involved in the biosynthesis of the Staphylococcus epidermidis polysaccharide intercellular adhesin. J Biol Chem 273(29): 18586-18593. doi: 10.1074/jbc.273.29.18586

126. Vuong C, Kocianova S, Voyich JM, Yao Y, Fischer ER, DeLeo FR, Otto $M$ (2004). A crucial role for exopolysaccharide modification in bacterial biofilm formation, immune evasion, and virulence. J Biol Chem 279(52): 54881-54886. doi: 10.1074/jbc.M411374200

127. Sarkar S (2020). Release mechanisms and molecular interactions of Pseudomonas aeruginosa extracellular DNA. Appl Microbiol Biotechnol 104(15): 6549-6564. doi: 10.1007/s00253-020-10687-9

128. Whitchurch CB, Tolker-Nielsen T, Ragas PC, Mattick JS (2002). Extracellular DNA required for bacterial biofilm formation. Science 295(5559): 1487. doi: 10.1126/science.295.5559.1487

129. Kiedrowski MR, Kavanaugh JS, Malone CL, Mootz JM, Voyich JM, Smeltzer MS, Bayles KW, Horswill AR (2011). Nuclease modulates biofilm formation in community-associated methicillin-resistant Staphylococcus aureus. PLoS One 6(11): e26714. doi: 10.1371/journal.pone.0026714

130. Beenken KE, Spencer H, Griffin LM, Smeltzer MS (2012). Impact of extracellular nuclease production on the biofilm phenotype of Staphylococcus aureus under in vitro and in vivo conditions. Infect Immun 80(5): 1634-1638. doi: 10.1128/IAI.06134-11

131. Cherny KE, Sauer K (2019). Pseudomonas aeruginosa Requires the DNA-Specific Endonuclease EndA To Degrade Extracellular Genomic DNA To Disperse from the Biofilm. J Bacteriol 201(18): e0005919. doi: 10.1128/JB.00059-19

132. Gumpenberger T, Vorkapic D, Zingl FG, Pressler K, Lackner S, Seper A, Reidl J, Schild S (2016). Nucleoside uptake in Vibrio cholerae and its role in the transition fitness from host to environment. Mol Microbiol 99(3): 470-483. doi: 10.1111/mmi.13143

133. Mulcahy H, Charron-Mazenod L, Lewenza S (2010). Pseudomonas aeruginosa produces an extracellular deoxyribonuclease that is required for utilization of DNA as a nutrient source. Environ Microbiol 12(6): 1621-1629. doi: 10.1111/j.1462-2920.2010.02208.x

134. McDonough E, Kamp H, Camilli A (2016). Vibrio cholerae phosphatases required for the utilization of nucleotides and extracellular DNA as phosphate sources. Mol Microbiol 99(3): 453-469. doi: 10.1111/mmi.13128

135. Pratt JT, McDonough E, Camilli A (2009). PhoB regulates motility, biofilms, and cyclic di-GMP in Vibrio cholerae. J Bacteriol 191(21): 6632-6642. doi: 10.1128/JB.00708-09

136. Sultan SZ, Silva AJ, Benitez JA (2010). The PhoB regulatory system modulates biofilm formation and stress response in El Tor biotype
Vibrio cholerae. FEMS Microbiol Lett 302(1): 22-31. doi: 10.1111/j.1574-6968.2009.01837.x

137. Fuxman Bass JI, Russo DM, Gabelloni ML, Geffner JR, Giordano M, Catalano M, Zorreguieta A, Trevani AS (2010). Extracellular DNA: a major proinflammatory component of Pseudomonas aeruginosa biofilms. J Immunol 184(11): 6386-6395. doi: 10.4049/jimmunol.0901640

138. Mewborn L, Benitez JA, Silva AJ (2017). Flagellar motility, extracellular proteases and Vibrio cholerae detachment from abiotic and biotic surfaces. Microb Pathog 113: 17-24. doi 10.1016/j.micpath.2017.10.016

139. Yu S, Su T, Wu H, Liu S, Wang D, Zhao T, Jin Z, Du W, Zhu MJ, Chua SL, Yang L, Zhu D, Gu L, Ma LZ (2015). PsIG, a self-produced glycosyl hydrolase, triggers biofilm disassembly by disrupting exopolysaccharide matrix. Cell Res 25(12): 1352-1367. doi: 10.1038/cr.2015.129

140. Esoda CN, Kuehn MJ (2019). Pseudomonas aeruginosa Leucine Aminopeptidase Influences Early Biofilm Composition and Structure via Vesicle-Associated Antibiofilm Activity. mBio 10(6): e02548-19. doi: 10.1128/mBio.02548-19

141. Zhao T, Zhang Y, Wu H, Wang D, Chen Y, Zhu MJ, Ma LZ (2018). Extracellular aminopeptidase modulates biofilm development of Pseudomonas aeruginosa by affecting matrix exopolysaccharide and bacterial cell death. Environ Microbiol Rep 10(5): 583-593. doi: 10.1111/1758-2229.12682

142. Boles BR, Horswill AR (2008). Agr-mediated dispersal of Staphylococcus aureus biofilms. PLoS Pathog 4(4): e1000052. doi: 10.1371/journal.ppat.1000052

143. Maestre-Reyna $M$, Wu WJ, Wang AH (2013). Structural insights into RbmA, a biofilm scaffolding protein of $V$. cholerae. PLoS One 8(12): e82458. doi: 10.1371/journal.pone.0082458

144. Duperthuy $M$, Sjostrom AE, Sabharwal D, Damghani F, Uhlin BE, Wai SN (2013). Role of the Vibrio cholerae matrix protein Bap1 in cross-resistance to antimicrobial peptides. PLoS Pathog 9(10): e1003620. doi: 10.1371/journal.ppat.1003620

145. Baneres JL, Roquet F, Martin A, Parello J (2000). A minimized human integrin alpha(5)beta(1) that retains ligand recognition. J Biol Chem 275(8): 5888-5903. doi: 10.1074/jbc.275.8.5888

146. Moorthy S, Watnick PI (2005). Identification of novel stagespecific genetic requirements through whole genome transcription profiling of Vibrio cholerae biofilm development. Mol Microbiol 57(6) 1623-1635. doi: 10.1111/j.1365-2958.2005.04797.x

147. Hynes RO (1992). Integrins: versatility, modulation, and signaling in cell adhesion. Cell 69(1): 11-25. doi: 10.1016/0092-8674(92)90115-s

148. Hynes RO (2002). Integrins: bidirectional, allosteric signaling machines. Cell 110(6): 673-687. doi: 10.1016/s0092-8674(02)00971-6

149. Sankaranarayanan R, Sekar K, Banerjee R, Sharma V, Surolia A, Vijayan $M$ (1996). A novel mode of carbohydrate recognition in jacalin, a Moraceae plant lectin with a beta-prism fold. Nat Struct Biol 3(7): 596-603. doi: 10.1038/nsb0796-596

150. Sikora AE, Zielke RA, Lawrence DA, Andrews PC, Sandkvist M (2011). Proteomic analysis of the Vibrio cholerae type II secretome reveals new proteins, including three related serine proteases. J Biol Chem 286(19): 16555-16566. doi: 10.1074/jbc.M110.211078

151. Johnson TL, Fong JC, Rule C, Rogers A, Yildiz FH, Sandkvist M (2014). The Type II secretion system delivers matrix proteins for biofilm formation by Vibrio cholerae. J Bacteriol 196(24): 4245-4252. doi: 10.1128/JB.01944-14

152. Vorkapic D, Mitterer F, Pressler K, Leitner DR, Anonsen JH, Liesinger L, Mauerhofer LM, Kuehnast T, Toeglhofer M, Schulze A, Zingl FG, Feldman MF, Reidl J, Birner-Gruenberger R, Koomey M, Schild S (2019). A Broad Spectrum Protein Glycosylation System Influ- 
ences Type II Protein Secretion and Associated Phenotypes in Vibrio cholerae. Front Microbiol 10: 2780. doi: 10.3389/fmicb.2019.02780

153. Glick J, Garber N (1983). The intracellular localization of Pseudomonas aeruginosa lectins. J Gen Microbiol 129(10): 3085-3090. doi: 10.1099/00221287-129-10-3085

154. Tielker D, Hacker S, Loris R, Strathmann M, Wingender J, Wilhelm $S$, Rosenau $F$, Jaeger KE (2005). Pseudomonas aeruginosa lectin LecB is located in the outer membrane and is involved in biofilm formation. Microbiology (Reading) 151(Pt 5): 1313-1323. doi: 10.1099/mic.0.27701-0

155. Laughlin RS, Musch MW, Hollbrook CJ, Rocha FM, Chang EB, Alverdy JC (2000). The key role of Pseudomonas aeruginosa PA-I lectin on experimental gut-derived sepsis. Ann Surg 232(1): 133-142. doi: 10.1097/00000658-200007000-00019

156. Chemani C, Imberty A, de Bentzmann S, Pierre M, Wimmerova M, Guery BP, Faure K (2009). Role of LecA and LecB lectins in Pseudomonas aeruginosa-induced lung injury and effect of carbohydrate ligands. Infect Immun 77(5): 2065-2075. doi: 10.1128/IAI.01204-08

157. Diggle SP, Stacey RE, Dodd C, Camara M, Williams P, Winzer K (2006). The galactophilic lectin, LecA, contributes to biofilm development in Pseudomonas aeruginosa. Environ Microbiol 8(6): 1095-1104. doi: 10.1111/j.1462-2920.2006.001001.x

158. Garber N, Guempel U, Belz A, Gilboa-Garber N, Doyle RJ (1992). On the specificity of the D-galactose-binding lectin (PA-I) of Pseudomonas aeruginosa and its strong binding to hydrophobic derivatives of D-galactose and thiogalactose. Biochim Biophys Acta 1116(3): 331333. doi: 10.1016/0304-4165(92)90048-y

159. Blanchard B, Imberty A, Varrot A (2014). Secondary sugar binding site identified for LecA lectin from Pseudomonas aeruginosa. Proteins 82(6): 1060-1065. doi: 10.1002/prot.24430

160. Mitchell E, Houles C, Sudakevitz D, Wimmerova M, Gautier C, Perez S, Wu AM, Gilboa-Garber N, Imberty A (2002). Structural basis for oligosaccharide-mediated adhesion of Pseudomonas aeruginosa in the lungs of cystic fibrosis patients. Nat Struct Biol 9(12): 918-921. doi: $10.1038 /$ nsb865

161. Passos da Silva D, Matwichuk ML, Townsend DO, Reichhardt C, Lamba D, Wozniak DJ, Parsek MR (2019). The Pseudomonas aeruginosa lectin LecB binds to the exopolysaccharide Psl and stabilizes the biofilm matrix. Nat Commun 10(1): 2183. doi: 10.1038/s41467-01910201-4

162. Loris R, Tielker D, Jaeger KE, Wyns L (2003). Structural basis of carbohydrate recognition by the lectin LecB from Pseudomonas aeruginosa. J Mol Biol 331(4): 861-870. doi: 10.1016/s00222836(03)00754-x

163. Funken $H$, Bartels KM, Wilhelm S, Brocker $M$, Bott $M$, Bains $M$, Hancock RE, Rosenau F, Jaeger KE (2012). Specific association of lectin LecB with the surface of Pseudomonas aeruginosa: role of outer membrane protein OprF. PLoS One 7(10): e46857. doi: 10.1371/journal.pone.0046857

164. Corrigan RM, Rigby D, Handley P, Foster TJ (2007). The role of Staphylococcus aureus surface protein SasG in adherence and biofilm formation. Microbiology (Reading) 153(Pt 8): 2435-2446. doi: 10.1099/mic.0.2007/006676-0

165. Yarawsky AE, English LR, Whitten ST, Herr AB (2017). The Proline/Glycine-Rich Region of the Biofilm Adhesion Protein Aap Forms an Extended Stalk that Resists Compaction. J Mol Biol 429(2): 261-279. doi: 10.1016/j.jmb.2016.11.017

166. Cucarella C, Solano C, Valle J, Amorena B, Lasa I, Penades JR (2001). Bap, a Staphylococcus aureus surface protein involved in biofilm formation. J Bacteriol 183(9): 2888-2896. doi: 10.1128/JB.183.9.2888-2896.2001
167. Merino N, Toledo-Arana A, Vergara-Irigaray M, Valle J, Solano C, Calvo E, Lopez JA, Foster TJ, Penades JR, Lasa I (2009). Protein Amediated multicellular behavior in Staphylococcus aureus. J Bacteriol 191(3): 832-843. doi: 10.1128/JB.01222-08

168. Lembre P, Vendrely C, Martino PD (2014). Identification of an amyloidogenic peptide from the Bap protein of Staphylococcus epidermidis. Protein Pept Lett 21(1): 75-79. doi: 10.2174/09298665113209990072

169. Cucarella C, Tormo MA, Knecht E, Amorena B, Lasa I, Foster TJ, Penades JR (2002). Expression of the biofilm-associated protein interferes with host protein receptors of Staphylococcus aureus and alters the infective process. Infect Immun 70(6): 3180-3186. doi: 10.1128/iai.70.6.3180-3186.2002

170. Reichhardt C, Fong JC, Yildiz F, Cegelski L (2015). Characterization of the Vibrio cholerae extracellular matrix: a top-down solid-state NMR approach. Biochim Biophys Acta 1848(1 Pt B): 378-383. doi: 10.1016/j.bbamem.2014.05.030

171. Leck C, Bigg EK (2005). Biogenic particles in the surface microlayer and overlaying atmosphere in the central Arctic Ocean during summer. Tellus B: Chemical and Physical Meteorology 57(4): 305316. doi: 10.3402/tellusb.v57i4.16546

172. Davey ME, Caiazza NC, O'Toole GA (2003). Rhamnolipid surfactant production affects biofilm architecture in Pseudomonas aeruginosa PAO1. J Bacteriol 185(3): 1027-1036. doi: 10.1128/jb.185.3.1027-1036.2003

173. Ochsner UA, Koch AK, Fiechter A, Reiser J (1994). Isolation and characterization of a regulatory gene affecting rhamnolipid biosurfactant synthesis in Pseudomonas aeruginosa. J Bacteriol 176(7): 2044 2054. doi: 10.1128/jb.176.7.2044-2054.1994

174. Gross M, Cramton SE, Gotz F, Peschel A (2001). Key role of teichoic acid net charge in Staphylococcus aureus colonization of artificial surfaces. Infect Immun 69(5): 3423-3426. doi: 10.1128/IAI.69.5.3423-3426.2001

175. Jabbouri S, Sadovskaya I (2010). Characteristics of the biofilm matrix and its role as a possible target for the detection and eradication of Staphylococcus epidermidis associated with medical implant infections. FEMS Immunol Med Microbiol 59(3): 280-291. doi: 10.1111/j.1574-695X.2010.00695.x

176. Hussain M, Heilmann C, Peters G, Herrmann M (2001). Teichoic acid enhances adhesion of Staphylococcus epidermidis to immobilized fibronectin. Microb Pathog 31(6): 261-270. doi: 10.1006/mpat.2001.0469

177. McDougald D, Rice SA, Barraud N, Steinberg PD, Kjelleberg S (2011). Should we stay or should we go: mechanisms and ecological consequences for biofilm dispersal. Nat Rev Microbiol 10(1): 39-50. doi: 10.1038/nrmicro2695

178. Kierek K, Watnick PI (2003). The Vibrio cholerae 0139 O-antigen polysaccharide is essential for $\mathrm{Ca} 2+-$ dependent biofilm development in sea water. Proc Natl Acad Sci U S A 100(24): 14357-14362. doi: 10.1073/pnas. 2334614100

179. Singh PK, Bartalomej S, Hartmann R, Jeckel H, Vidakovic L, Nadell CD, Drescher K (2017). Vibrio cholerae Combines Individual and Collective Sensing to Trigger Biofilm Dispersal. Curr Biol 27(21): 3359-3366 e3357. doi: 10.1016/j.cub.2017.09.041

180. Yildiz FH, Schoolnik GK (1998). Role of rpoS in stress survival and virulence of Vibrio cholerae. J Bacteriol 180(4): 773-784. doi: 10.1128/JB.180.4.773-784.1998

181. Hammer BK, Bassler BL (2003). Quorum sensing controls biofilm formation in Vibrio cholerae. Mol Microbiol 50(1): 101-104. doi: 10.1046/j.1365-2958.2003.03688.x 
182. Boyd A, Chakrabarty AM (1994). Role of alginate lyase in cell detachment of Pseudomonas aeruginosa. Appl Environ Microbiol 60(7): 2355-2359. doi: 10.1128/AEM.60.7.2355-2359.1994

183. Sauer K, Cullen MC, Rickard AH, Zeef LA, Davies DG, Gilbert P (2004). Characterization of nutrient-induced dispersion in Pseudomonas aeruginosa PAO1 biofilm. J Bacteriol 186(21): 7312-7326. doi: 10.1128/JB.186.21.7312-7326.2004

184. Harmsen M, Yang L, Pamp SJ, Tolker-Nielsen T (2010). An update on Pseudomonas aeruginosa biofilm formation, tolerance, and dispersal. FEMS Immunol Med Microbiol 59(3): 253-268. doi: 10.1111/j.1574-695X.2010.00690.x

185. Boles BR, Thoendel M, Singh PK (2005). Rhamnolipids mediate detachment of Pseudomonas aeruginosa from biofilms. Mol Microbiol 57(5): 1210-1223. doi: 10.1111/j.1365-2958.2005.04743.x

186. Webb JS, Thompson LS, James S, Charlton T, Tolker-Nielsen T, Koch B, Givskov M, Kjelleberg S (2003). Cell death in Pseudomonas aeruginosa biofilm development. J Bacteriol 185(15): 4585-4592. doi: 10.1128/jb.185.15.4585-4592.2003

187. Shaw L, Golonka E, Potempa J, Foster SJ (2004). The role and regulation of the extracellular proteases of Staphylococcus aureus. Microbiology (Reading) 150(Pt 1): 217-228. doi: 10.1099/mic.0.26634-0

188. Marti M, Trotonda MP, Tormo-Mas MA, Vergara-Irigaray M, Cheung AL, Lasa I, Penades JR (2010). Extracellular proteases inhibit protein-dependent biofilm formation in Staphylococcus aureus. Microbes Infect 12(1): 55-64. doi: 10.1016/j.micinf.2009.10.005

189. Otto M (2009). Staphylococcus epidermidis--the 'accidental' pathogen. Nat Rev Microbiol 7(8): 555-567. doi 10.1038/nrmicro2182

190. Mootz JM, Malone CL, Shaw LN, Horswill AR (2013). Staphopains modulate Staphylococcus aureus biofilm integrity. Infect Immun 81(9): 3227-3238. doi: 10.1128/IAI.00377-13

191. Thoendel M, Kavanaugh JS, Flack CE, Horswill AR (2011). Peptide signaling in the staphylococci. Chem Rev 111(1): 117-151. doi: $10.1021 / \mathrm{cr} 100370 n$

192. Lister JL, Horswill AR (2014). Staphylococcus aureus biofilms: recent developments in biofilm dispersal. Front Cell Infect Microbio 4: 178. doi: 10.3389/fcimb.2014.00178

193. Sugimoto S, Iwamoto T, Takada K, Okuda K, Tajima A, Iwase T, Mizunoe Y (2013). Staphylococcus epidermidis Esp degrades specific proteins associated with Staphylococcus aureus biofilm formation and host-pathogen interaction. J Bacteriol 195(8): 1645-1655. doi: 10.1128/JB.01672-12

194. Chen C, Krishnan V, Macon K, Manne K, Narayana SV, Schneewind O (2013). Secreted proteases control autolysin-mediated biofilm growth of Staphylococcus aureus. J Biol Chem 288(41): 2944029452. doi: 10.1074/jbc.M113.502039

195. Donelli G, Francolini I, Romoli D, Guaglianone E, Piozzi A, Ragunath C, Kaplan JB (2007). Synergistic activity of dispersin B and cefamandole nafate in inhibition of staphylococcal biofilm growth on polyurethanes. Antimicrob Agents Chemother 51(8): 2733-2740. doi: 10.1128/AAC.01249-06

196. Pacheco AR, Sperandio V (2009). Inter-kingdom signaling: chemical language between bacteria and host. Curr Opin Microbiol 12(2) 192-198. doi: 10.1016/j.mib.2009.01.006

197. Rutherford ST, Bassler BL (2012). Bacterial quorum sensing: its role in virulence and possibilities for its control. Cold Spring Harb Perspect Med 2(11): a012427. doi: 10.1101/cshperspect.a012427
198. Jung SA, Hawver LA, Ng WL (2016). Parallel quorum sensing signaling pathways in Vibrio cholerae. Curr Genet 62(2): 255-260. doi: 10.1007/s00294-015-0532-8

199. Watve S, Barrasso K, Jung SA, Davis KJ, Hawver LA, Khataokar A, Palaganas RG, Neiditch MB, Perez LJ, Ng W-L (2019). Ethanolamine regulates CqsR quorum-sensing signaling in Vibrio cholerae. bioRxiv: 589390. doi: 10.1101/589390

200. Hossain S, Heckler I, Boon EM (2018). Discovery of a Nitric Oxide Responsive Quorum Sensing Circuit in Vibrio cholerae. ACS Chem Biol 13(8): 1964-1969. doi: 10.1021/acschembio.8b00360

201. Ng WL, Bassler BL (2009). Bacterial quorum-sensing network architectures. Annu Rev Genet 43: 197-222. doi: 10.1146/annurevgenet-102108-134304

202. Waters CM, Lu W, Rabinowitz JD, Bassler BL (2008). Quorum sensing controls biofilm formation in Vibrio cholerae through modulation of cyclic di-GMP levels and repression of vpsT. J Bacteriol 190(7): 2527-2536. doi: 10.1128/JB.01756-07

203. Yildiz FH, Liu XS, Heydorn A, Schoolnik GK (2004). Molecular analysis of rugosity in a Vibrio cholerae $01 \mathrm{El}$ Tor phase variant. Mol Microbiol 53(2): 497-515. doi: 10.1111/j.1365-2958.2004.04154.x

204. Liu Z, Hsiao A, Joelsson A, Zhu J (2006). The transcriptional regulator $V q m A$ increases expression of the quorum-sensing activator HapR in Vibrio cholerae. J Bacteriol 188(7): 2446-2453. doi: 10.1128/JB.188.7.2446-2453.2006

205. Liang W, Pascual-Montano A, Silva AJ, Benitez JA (2007). The cyclic AMP receptor protein modulates quorum sensing, motility and multiple genes that affect intestinal colonization in Vibrio cholerae. Microbiology (Reading) 153(Pt 9): 2964-2975. doi: 10.1099/mic.0.2007/006668-0

206. Lee J, Zhang $L$ (2015). The hierarchy quorum sensing network in Pseudomonas aeruginosa. Protein Cell 6(1): 26-41. doi: 10.1007/s13238-014-0100-x

207. Schuster M, Greenberg EP (2006). A network of networks: quorum-sensing gene regulation in Pseudomonas aeruginosa. Int $\mathbf{J} \mathbf{~ M e d}$ Microbiol 296(2-3): 73-81. doi: 10.1016/j.ijmm.2006.01.036

208. Gallagher LA, McKnight SL, Kuznetsova MS, Pesci EC, Manoil C (2002). Functions required for extracellular quinolone signaling by Pseudomonas aeruginosa. J Bacteriol 184(23): 6472-6480. doi: 10.1128/jb.184.23.6472-6480.2002

209. Mashburn LM, Whiteley M (2005). Membrane vesicles traffic signals and facilitate group activities in a prokaryote. Nature 437(7057): 422-425. doi: 10.1038/nature03925

210. Dusane DH, Zinjarde SS, Venugopalan VP, McLean RJ, Weber MM, Rahman PK (2010). Quorum sensing: implications on rhamnolipid biosurfactant production. Biotechnol Genet Eng Rev 27: 159-184. doi: 10.1080/02648725.2010.10648149

211. D'Argenio DA, Calfee MW, Rainey PB, Pesci EC (2002). Autolysis and autoaggregation in Pseudomonas aeruginosa colony morphology mutants. J Bacteriol 184(23): 6481-6489. doi: 10.1128/jb.184.23.64816489.2002

212. Patriquin GM, Banin E, Gilmour C, Tuchman R, Greenberg EP, Poole K (2008). Influence of quorum sensing and iron on twitching motility and biofilm formation in Pseudomonas aeruginosa. J Bacteriol 190(2): 662-671. doi: 10.1128/JB.01473-07

213. Le KY, Otto M (2015). Quorum-sensing regulation in staphylococci-an overview. Front Microbiol 6: 1174. doi 10.3389/fmicb.2015.01174

214. Novick RP (1990). Molecular biology of the staphylococci. VCH Publishers, Inc., New York. 
215. Ji G, Beavis RC, Novick RP (1995). Cell density control of staphylococcal virulence mediated by an octapeptide pheromone. Proc Natl Acad Sci U S A 92(26): 12055-12059. doi: 10.1073/pnas.92.26.12055

216. Zhang L, Ji G (2004). Identification of a staphylococcal AgrB segment(s) responsible for group-specific processing of AgrD by gene swapping. J Bacteriol 186(20): 6706-6713. doi: 10.1128/JB.186.20.6706-6713.2004

217. Kavanaugh JS, Thoendel M, Horswill AR (2007). A role for type I signal peptidase in Staphylococcus aureus quorum sensing. Mol Microbiol 65(3): 780-798. doi: 10.1111/j.1365-2958.2007.05830.x

218. Lina G, Jarraud S, Ji G, Greenland T, Pedraza A, Etienne J, Novick $R P$, Vandenesch $F$ (1998). Transmembrane topology and histidine protein kinase activity of AgrC, the agr signal receptor in Staphylococcus aureus. Mol Microbiol 28(3): 655-662. doi: 10.1046/j.13652958.1998.00830.x

219. Novick RP, Projan SJ, Kornblum J, Ross HF, Ji G, Kreiswirth B, Vandenesch F, Moghazeh S (1995). The agr P2 operon: an autocatalytic sensory transduction system in Staphylococcus aureus. Mol Gen Genet 248(4): 446-458. doi: 10.1007/BF02191645

220. Queck SY, Jameson-Lee M, Villaruz AE, Bach TH, Khan BA, Sturdevant $D E$, Ricklefs SM, Li M, Otto M (2008). RNAlll-independent target gene control by the agr quorum-sensing system: insight into the evolution of virulence regulation in Staphylococcus aureus. Mol Cell 32(1): 150-158. doi: 10.1016/j.molcel.2008.08.005

221. Koenig RL, Ray JL, Maleki SJ, Smeltzer MS, Hurlburt BK (2004). Staphylococcus aureus AgrA binding to the RNAlll-agr regulatory region. J Bacteriol 186(22): 7549-7555. doi: 10.1128/JB.186.22.75497555.2004

222. Periasamy S, Joo HS, Duong AC, Bach TH, Tan VY, Chatterjee SS, Cheung GY, Otto M (2012). How Staphylococcus aureus biofilms develop their characteristic structure. Proc Natl Acad Sci U S A 109(4): 1281-1286. doi: 10.1073/pnas.1115006109

223. Otto M (2014). Phenol-soluble modulins. Int J Med Microbiol 304(2): 164-169. doi: 10.1016/j.ijmm.2013.11.019

224. Novick RP, Ross HF, Projan SJ, Kornblum J, Kreiswirth B, Moghazeh S (1993). Synthesis of staphylococcal virulence factors is controlled by a regulatory RNA molecule. EMBO J 12(10): 3967-3975. doi: 10.1002/j.1460-2075.1993.tb06074.x

225. Fechter $P$, Caldelari I, Lioliou E, Romby P (2014). Novel aspects of RNA regulation in Staphylococcus aureus. FEBS Lett 588(15): 25232529. doi: 10.1016/j.febslet.2014.05.037

226. Janzon L, Lofdahl S, Arvidson S (1989). Identification and nucleotide sequence of the delta-lysin gene, $h / d$, adjacent to the accessory gene regulator (agr) of Staphylococcus aureus. Mol Gen Genet 219(3): 480-485. doi: 10.1007/BF00259623

227. Vuong C, Kocianova S, Yao Y, Carmody AB, Otto M (2004). Increased colonization of indwelling medical devices by quorum-sensing mutants of Staphylococcus epidermidis in vivo. J Infect Dis 190(8): 1498-1505. doi: 10.1086/424487

228. Vuong C, Saenz HL, Gotz F, Otto M (2000). Impact of the agr quorum-sensing system on adherence to polystyrene in Staphylococcus aureus. J Infect Dis 182(6): 1688-1693. doi: 10.1086/317606

229. Vuong C, Gerke C, Somerville GA, Fischer ER, Otto M (2003). Quorum-sensing control of biofilm factors in Staphylococcus epidermidis. J Infect Dis 188(5): 706-718. doi: 10.1086/377239

230. Bassler BL, Greenberg EP, Stevens AM (1997). Cross-species induction of luminescence in the quorum-sensing bacterium Vibrio harveyi. J Bacteriol 179(12): 4043-4045. doi: 10.1128/jb.179.12.40434045.1997
231. Zhao L, Xue T, Shang F, Sun $H$, Sun B (2010). Staphylococcus aureus $\mathrm{Al}-2$ quorum sensing associates with the $\mathrm{KdpDE}$ two-component system to regulate capsular polysaccharide synthesis and virulence. Infect Immun 78(8): 3506-3515. doi: 10.1128/IAI.00131-10

232. Yu D, Zhao L, Xue T, Sun B (2012). Staphylococcus aureus autoinducer-2 quorum sensing decreases biofilm formation in an icaRdependent manner. BMC Microbiol 12: 288. doi: 10.1186/1471-218012-288

233. Xue T, Zhao L, Sun B (2013). LuxS/Al-2 system is involved in antibiotic susceptibility and autolysis in Staphylococcus aureus NCTC 8325. Int J Antimicrob Agents 41(1): 85-89. doi 10.1016/j.ijantimicag.2012.08.016

234. Li M, Villaruz AE, Vadyvaloo V, Sturdevant DE, Otto M (2008). Al2-dependent gene regulation in Staphylococcus epidermidis. BMC Microbiol 8: 4. doi: 10.1186/1471-2180-8-4

235. Winzer K, Hardie KR, Burgess N, Doherty N, Kirke D, Holden MTG, Linforth R, Cornell KA, Taylor AJ, Hill PJ, Williams P (2002). LuxS: its role in central metabolism and the in vitro synthesis of 4-hydroxy-5methyl-3(2H)-furanone. Microbiology (Reading) 148(Pt 4): 909-922. doi: 10.1099/00221287-148-4-909

236. Hengge R (2009). Principles of c-di-GMP signalling in bacteria. Nat Rev Microbiol 7(4): 263-273. doi: 10.1038/nrmicro2109

237. Galperin MY, Nikolskaya AN, Koonin EV (2001). Novel domains of the prokaryotic two-component signal transduction systems. FEMS Microbiol Lett 203(1): 11-21. doi: 10.1111/j.15746968.2001.tb10814.x

238. Beyhan S, Odell LS, Yildiz FH (2008). Identification and characterization of cyclic diguanylate signaling systems controlling rugosity in Vibrio cholerae. J Bacteriol 190(22): 7392-7405. doi: 10.1128/JB.00564-08

239. Townsley L, Yildiz FH (2015). Temperature affects c-di-GMP signalling and biofilm formation in Vibrio cholerae. Environ Microbiol 17(11): 4290-4305. doi: 10.1111/1462-2920.12799

240. Beyhan S, Bilecen K, Salama SR, Casper-Lindley C, Yildiz FH (2007). Regulation of rugosity and biofilm formation in Vibrio cholerae: comparison of VpsT and VpsR regulons and epistasis analysis of vpsT, vpsR, and hapR. J Bacteriol 189(2): 388-402. doi: 10.1128/JB.00981-06

241. Koestler BJ, Waters CM (2014). Bile acids and bicarbonate inversely regulate intracellular cyclic di-GMP in Vibrio cholerae. Infect Immun 82(7): 3002-3014. doi: 10.1128/IAI.01664-14

242. Cockerell SR, Rutkovsky AC, Zayner JP, Cooper RE, Porter LR, Pendergraft SS, Parker ZM, McGinnis MW, Karatan E (2014). Vibrio cholerae NspS, a homologue of $\mathrm{ABC}$-type periplasmic solute binding proteins, facilitates transduction of polyamine signals independent of their transport. Microbiology (Reading) 160(Pt 5): 832-843. doi: 10.1099/mic.0.075903-0

243. Hammer BK, Bassler BL (2007). Regulatory small RNAs circumvent the conventional quorum sensing pathway in pandemic Vibrio cholerae. Proc Natl Acad Sci U S A 104(27): 11145-11149. doi: 10.1073/pnas.0703860104

244. Pratt JT, Tamayo R, Tischler AD, Camilli A (2007). PilZ domain proteins bind cyclic diguanylate and regulate diverse processes in Vibrio cholerae. J Biol Chem 282(17): 12860-12870. doi: 10.1074/jbc.M611593200

245. Sudarsan N, Lee ER, Weinberg Z, Moy RH, Kim JN, Link KH, Breaker RR (2008). Riboswitches in eubacteria sense the second messenger cyclic di-GMP. Science 321(5887): 411-413. doi: 10.1126/science.1159519 
246. Krasteva PV, Fong JC, Shikuma NJ, Beyhan S, Navarro MV, Yildiz $\mathrm{FH}$, Sondermann H (2010). Vibrio cholerae VpsT regulates matrix production and motility by directly sensing cyclic di-GMP. Science 327(5967): 866-868. doi: 10.1126/science.1181185

247. Srivastava D, Harris RC, Waters CM (2011). Integration of cyclic di-GMP and quorum sensing in the control of vpsT and aphA in Vibrio cholerae. J Bacteriol 193(22): 6331-6341. doi: 10.1128/JB.05167-11

248. Amikam D, Galperin MY (2006). PilZ domain is part of the bacterial c-di-GMP binding protein. Bioinformatics 22(1): 3-6. doi: 10.1093/bioinformatics/bti739

249. Srivastava D, Hsieh ML, Khataokar A, Neiditch MB, Waters CM (2013). Cyclic di-GMP inhibits Vibrio cholerae motility by repressing induction of transcription and inducing extracellular polysaccharide production. Mol Microbiol 90(6): 1262-1276. doi: 10.1111/mmi.12432

250. Sloup RE, Konal AE, Severin GB, Korir ML, Bagdasarian MM, Bagdasarian M, Waters CM (2017). Cyclic Di-GMP and VpsR Induce the Expression of Type II Secretion in Vibrio cholerae. J Bacteriol 199(19): e00106-17. doi: 10.1128/JB.00106-17

251. Zamorano-Sanchez D, Fong JC, Kilic S, Erill I, Yildiz FH (2015). Identification and characterization of VpsR and VpsT binding sites in Vibrio cholerae. J Bacteriol 197(7): 1221-1235. doi: 10.1128/JB.0243914

252. Casper-Lindley C, Yildiz FH (2004). VpsT is a transcriptional regulator required for expression of vps biosynthesis genes and the development of rugose colonial morphology in Vibrio cholerae $01 \mathrm{El}$ Tor. J Bacteriol 186(5): 1574-1578. doi: 10.1128/jb.186.5.1574-1578.2004

253. Lauderdale KJ, Boles BR, Cheung AL, Horswill AR (2009). Interconnections between Sigma B, agr, and proteolytic activity in Staphylococcus aureus biofilm maturation. Infect Immun 77(4): 1623-1635. doi: 10.1128/IAI.01036-08

254. Basu Roy A, Sauer K (2014). Diguanylate cyclase NicD-based signalling mechanism of nutrient-induced dispersion by Pseudomonas aeruginosa. Mol Microbiol 94(4): 771-793. doi: 10.1111/mmi.12802

255. Valentini M, Filloux A (2016). Biofilms and Cyclic di-GMP (c-diGMP) Signaling: Lessons from Pseudomonas aeruginosa and Other Bacteria. J Biol Chem 291(24): 12547-12555. doi: 10.1074/jbc.R115.711507

256. Chou SH, Galperin MY (2016). Diversity of Cyclic Di-GMP-Binding Proteins and Mechanisms. J Bacteriol 198(1): 32-46. doi: 10.1128/JB.00333-15

257. Hay ID, Remminghorst $U$, Rehm BH (2009). MucR, a novel membrane-associated regulator of alginate biosynthesis in Pseudomonas aeruginosa. App Environ Microbiol 75(4): 1110-1120. doi: 10.1128/AEM.02416-08

258. Guvener ZT, Harwood CS (2007). Subcellular location characteristics of the Pseudomonas aeruginosa GGDEF protein, WspR, indicate that it produces cyclic-di-GMP in response to growth on surfaces. Mol Microbiol 66(6): 1459-1473. doi: 10.1111/j.1365-2958.2007.06008.x

259. Huangyutitham V, Guvener ZT, Harwood CS (2013). Subcellular clustering of the phosphorylated WspR response regulator protein stimulates its diguanylate cyclase activity. mBio 4(3): e00242-00213. doi: $10.1128 / \mathrm{mBio} .00242-13$

260. De N, Pirruccello M, Krasteva PV, Bae N, Raghavan RV, Sondermann $H$ (2008). Phosphorylation-independent regulation of the diguanylate cyclase WspR. PLoS Biol 6(3): e67. doi: 10.1371/journal.pbio.0060067

261. Kulasekara HD, Ventre I, Kulasekara BR, Lazdunski A, Filloux A, Lory $S$ (2005). A novel two-component system controls the expression of Pseudomonas aeruginosa fimbrial cup genes. Mol Microbiol 55(2): 368-380. doi: 10.1111/j.1365-2958.2004.04402.x
262. Rao F, Yang Y, Qi Y, Liang ZX (2008). Catalytic mechanism of cyclic di-GMP-specific phosphodiesterase: a study of the EAL domaincontaining RocR from Pseudomonas aeruginosa. J Bacteriol 190(10): 3622-3631. doi: 10.1128/JB.00165-08

263. Bernier SP, Ha DG, Khan W, Merritt JH, O'Toole GA (2011). Modulation of Pseudomonas aeruginosa surface-associated group behaviors by individual amino acids through c-di-GMP signaling. Res Microbiol 162(7): 680-688. doi: 10.1016/j.resmic.2011.04.014

264. Merritt JH, Ha DG, Cowles KN, Lu W, Morales DK, Rabinowitz J, Gitai Z, O'Toole GA (2010). Specific control of Pseudomonas aeruginosa surface-associated behaviors by two c-di-GMP diguanylate cyclases. mBio 1(4): e00183-10. doi: 10.1128/mBio.00183-10

265. Klebensberger J, Birkenmaier A, Geffers R, Kjelleberg S, Philipp B (2009). SiaA and SiaD are essential for inducing autoaggregation as a specific response to detergent stress in Pseudomonas aeruginosa Environ Microbiol 11(12): 3073-3086. doi: 10.1111/j.14622920.2009.02012.x

266. Petrova OE, Cherny KE, Sauer K (2014). The Pseudomonas aeruginosa diguanylate cyclase GcbA, a homolog of P. fluorescens GcbA, promotes initial attachment to surfaces, but not biofilm formation, via regulation of motility. J Bacteriol 196(15): 2827-2841. doi: 10.1128/JB.01628-14

267. Roy AB, Petrova OE, Sauer K (2012). The phosphodiesterase DipA (PA5017) is essential for Pseudomonas aeruginosa biofilm dispersion. J Bacteriol 194(11): 2904-2915. doi: 10.1128/JB.05346-11

268. An S, Wu J, Zhang LH (2010). Modulation of Pseudomonas aeruginosa biofilm dispersal by a cyclic-Di-GMP phosphodiesterase with a putative hypoxia-sensing domain. Appl Environ Microbiol 76(24): 8160-8173. doi: 10.1128/AEM.01233-10

269. Li Y, Heine S, Entian M, Sauer K, Frankenberg-Dinkel N (2013). NO-induced biofilm dispersion in Pseudomonas aeruginosa is mediated by an MHYT domain-coupled phosphodiesterase. J Bacteriol 195(16): 3531-3542. doi: 10.1128/JB.01156-12

270. Ueda A, Wood TK (2009). Connecting quorum sensing, c-di-GMP, pel polysaccharide, and biofilm formation in Pseudomonas aeruginosa through tyrosine phosphatase TpbA (PA3885). PLoS Pathog 5(6): e1000483. doi: 10.1371/journal.ppat.1000483

271. Merighi M, Lee VT, Hyodo M, Hayakawa Y, Lory S (2007). The second messenger bis-(3'-5')-cyclic-GMP and its PilZ domaincontaining receptor Alg44 are required for alginate biosynthesis in Pseudomonas aeruginosa. Mol Microbiol 65(4): 876-895. doi: 10.1111/j.1365-2958.2007.05817.x

272. Hickman JW, Harwood CS (2008). Identification of FleQ from Pseudomonas aeruginosa as a c-di-GMP-responsive transcription factor. Mol Microbiol 69(2): 376-389. doi: 10.1111/j.13652958.2008.06281.x

273. Su T, Liu S, Wang K, Chi K, Zhu D, Wei T, Huang Y, Guo L, Hu W, Xu $\mathrm{S}$, Lin Z, Gu L (2015). The REC domain mediated dimerization is critical for FleQ from Pseudomonas aeruginosa to function as a c-di-GMP receptor and flagella gene regulator. J Struct Biol 192(1): 1-13. doi: 10.1016/j.jsb.2015.09.002

274. Trampari E, Stevenson CE, Little RH, Wilhelm T, Lawson DM, Malone JG (2015). Bacterial rotary export ATPases are allosterically regulated by the nucleotide second messenger cyclic-di-GMP. J Biol Chem 290(40): 24470-24483. doi: 10.1074/jbc.M115.661439

275. Purcell EB, Tamayo R (2016). Cyclic diguanylate signaling in Grampositive bacteria. FEMS Microbiol Rev 40(5): 753-773. doi: 10.1093/femsre/fuw013

276. Holland LM, O'Donnell ST, Ryjenkov DA, Gomelsky L, Slater SR, Fey PD, Gomelsky M, O'Gara JP (2008). A staphylococcal GGDEF do- 
main protein regulates biofilm formation independently of cyclic dimeric GMP. J Bacteriol 190(15): 5178-5189. doi: 10.1128/JB.00375-08

277. Fischer A, Kambara K, Meyer H, Stenz L, Bonetti EJ, Girard M, Lalk M, Francois P, Schrenzel J (2014). GdpS contributes to Staphylococcus aureus biofilm formation by regulation of eDNA release. Int J Med Microbiol 304(3-4): 284-299. doi: 10.1016/j.ijmm.2013.10.010

278. Shao $Y$, Bassler BL (2012). Quorum-sensing non-coding small RNAs use unique pairing regions to differentially control mRNA targets. Mol Microbiol 83(3): 599-611. doi: 10.1111/j.13652958.2011.07959.x

279. Waters CM, Bassler BL (2005). Quorum sensing: cell-to-cell communication in bacteria. Annu Rev Cell Dev Biol 21: 319-346. doi: 10.1146/annurev.cellbio.21.012704.131001

280. Lenz DH, Mok KC, Lilley BN, Kulkarni RV, Wingreen NS, Bassler BL (2004). The small RNA chaperone $\mathrm{Hfq}$ and multiple small RNAs control quorum sensing in Vibrio harveyi and Vibrio cholerae. Cell 118(1): 6982. doi: 10.1016/j.cell.2004.06.009

281. Feng L, Rutherford ST, Papenfort K, Bagert JD, van Kessel JC, Tirrell DA, Wingreen NS, Bassler BL (2015). A qrr noncoding RNA deploys four different regulatory mechanisms to optimize quorumsensing dynamics. Cell 160(1-2): 228-240. doi: 10.1016/j.cell.2014.11.051

282. Yang M, Frey EM, Liu Z, Bishar R, Zhu J (2010). The virulence transcriptional activator AphA enhances biofilm formation by Vibrio cholerae by activating expression of the biofilm regulator VpsT. Infect Immun 78(2): 697-703. doi: 10.1128/IAI.00429-09

283. Papenfort K, Forstner KU, Cong JP, Sharma CM, Bassler BL (2015). Differential RNA-seq of Vibrio cholerae identifies the VqmR small RNA as a regulator of biofilm formation. Proc Natl Acad Sci U S A 112(7): E766-775. doi: 10.1073/pnas.1500203112

284. Lenz DH, Miller MB, Zhu J, Kulkarni RV, Bassler BL (2005). CsrA and three redundant small RNAs regulate quorum sensing in Vibrio cholerae. Mol Microbiol 58(4): 1186-1202. doi: 10.1111/j.13652958.2005.04902.x

285. Mey AR, Butz HA, Payne SM (2015). Vibrio cholerae CsrA Regulates ToxR Levels in Response to Amino Acids and Is Essential for Virulence. mBio 6(4): e01064. doi: 10.1128/mBio.01064-15

286. Tsou AM, Liu Z, Cai T, Zhu J (2011). The VarS/VarA twocomponent system modulates the activity of the Vibrio cholerae quorum-sensing transcriptional regulator HapR. Microbiology (Reading) 157(Pt 6): 1620-1628. doi: 10.1099/mic.0.046235-0

287. Janssen KH, Diaz MR, Gode CJ, Wolfgang MC, Yahr TL (2018). RsmV, a Small Noncoding Regulatory RNA in Pseudomonas aeruginosa That Sequesters RsmA and RsmF from Target mRNAs. J Bacteriol 200(16): e00277-18. doi: 10.1128/JB.00277-18

288. Valverde C, Heeb S, Keel C, Haas D (2003). RsmY, a small regulatory RNA, is required in concert with RsmZ for GacA-dependent expression of biocontrol traits in Pseudomonas fluorescens $\mathrm{CHAO}$. Mol Microbiol 50(4): 1361-1379. doi: 10.1046/j.1365-2958.2003.03774.x

289. Marden JN, Diaz MR, Walton WG, Gode CJ, Betts L, Urbanowski ML, Redinbo MR, Yahr TL, Wolfgang MC (2013). An unusual CsrA family member operates in series with RsmA to amplify posttranscriptional responses in Pseudomonas aeruginosa. Proc Natl Acad Sci U S A 110(37): 15055-15060. doi: 10.1073/pnas.1307217110

290. Miller CL, Romero M, Karna SL, Chen T, Heeb S, Leung KP (2016). RsmW, Pseudomonas aeruginosa small non-coding RsmA-binding RNA upregulated in biofilm versus planktonic growth conditions. BMC Microbiol 16(1): 155. doi: 10.1186/s12866-016-0771-y
291. Brencic A, Lory S (2009). Determination of the regulon and identification of novel mRNA targets of Pseudomonas aeruginosa RsmA Mol Microbiol 72(3): 612-632. doi: 10.1111/j.1365-2958.2009.06670.x

292. Irie Y, Starkey M, Edwards AN, Wozniak DJ, Romeo T, Parsek MR (2010). Pseudomonas aeruginosa biofilm matrix polysaccharide Psl is regulated transcriptionally by RpoS and post-transcriptionally by RsmA. Mol Microbiol 78(1): 158-172. doi: 10.1111/j.13652958.2010.07320.x

293. Lapouge K, Schubert M, Allain FH, Haas D (2008). Gac/Rsm signal transduction pathway of gamma-proteobacteria: from RNA recognition to regulation of social behaviour. Mol Microbiol 67(2): 241-253. doi: 10.1111/j.1365-2958.2007.06042.x

294. Goodman AL, Kulasekara B, Rietsch A, Boyd D, Smith RS, Lory S (2004). A signaling network reciprocally regulates genes associated with acute infection and chronic persistence in Pseudomonas aeruginosa. Dev Cell 7(5): 745-754. doi: 10.1016/j.devcel.2004.08.020

295. Morris ER, Hall G, Li C, Heeb S, Kulkarni RV, Lovelock L, Silistre H, Messina M, Camara M, Emsley J, Williams P, Searle MS (2013). Structural rearrangement in an RsmA/CsrA ortholog of Pseudomonas aeruginosa creates a dimeric RNA-binding protein, RsmN. Structure 21(9): 1659-1671. doi: 10.1016/j.str.2013.07.007

296. Pusic P, Tata M, Wolfinger MT, Sonnleitner E, Haussler S, Blasi U (2016). Cross-regulation by CrCZ RNA controls anoxic biofilm formation in Pseudomonas aeruginosa. Sci Rep 6: 39621. doi: 10.1038/srep39621

297. Sonnleitner $E$, Wulf $A$, Campagne $S$, Pei XY, Wolfinger MT, Forlani G, Prindl K, Abdou L, Resch A, Allain FH, Luisi BF, Urlaub H, Blasi U (2018). Interplay between the catabolite repression control protein $\mathrm{CrC}, \mathrm{Hfq}$ and RNA in Hfq-dependent translational regulation in Pseudomonas aeruginosa. Nucleic Acids Res 46(3): 1470-1485. doi: 10.1093/nar/gkx1245

298. Sonnleitner E, Gonzalez N, Sorger-Domenigg T, Heeb S, Richter AS, Backofen R, Williams P, Huttenhofer A, Haas D, Blasi U (2011). The small RNA PhrS stimulates synthesis of the Pseudomonas aeruginosa quinolone signal. Mol Microbiol 80(4): 868-885. doi: 10.1111/j.13652958.2011.07620.x

299. Romilly C, Caldelari I, Parmentier D, Lioliou E, Romby P, Fechter $P$ (2012). Current knowledge on regulatory RNAs and their machineries in Staphylococcus aureus. RNA Biol 9(4): 402-413. doi 10.4161/rna.20103

300. Romilly C, Chevalier C, Marzi S, Masquida B, Geissmann T, Vandenesch F, Westhof E, Romby P (2012). Loop-loop interactions involved in antisense regulation are processed by the endoribonuclease III in Staphylococcus aureus. RNA Biol 9(12): 1461-1472. doi: $10.4161 /$ rna. 22710

301. Svenningsen SL (2018). Small RNA-Based Regulation of Bacterial Quorum Sensing and Biofilm Formation. Microbiol Spectr 6(4). doi: 10.1128/microbiolspec.RWR-0017-2018

302. Mootz JM, Benson MA, Heim CE, Crosby HA, Kavanaugh JS, Dunman PM, Kielian T, Torres VJ, Horswill AR (2015). Rot is a key regulator of Staphylococcus aureus biofilm formation. Mol Microbiol 96(2): 388404. doi: 10.1111/mmi.12943

303. Jiang Q, Jin Z, Sun B (2018). MgrA Negatively Regulates Biofilm Formation and Detachment by Repressing the Expression of psm Operons in Staphylococcus aureus. Appl Environ Microbiol 84(16): e01008-18. doi: 10.1128/AEM.01008-18

304. Ruiz de los Mozos I, Vergara-Irigaray M, Segura V, Villanueva M, Bitarte N, Saramago M, Domingues S, Arraiano CM, Fechter P, Romby P, Valle J, Solano C, Lasa I, Toledo-Arana A (2013). Base pairing interaction between $5^{\prime}$ - and $3^{\prime}$-UTRs controls icaR mRNA translation in 
Staphylococcus aureus. PLoS Genet 9(12): e1004001. doi: 10.1371/journal.pgen.1004001

305. Kim S, Reyes D, Beaume M, Francois $P$, Cheung A (2014). Contribution of teg49 small RNA in the 5' upstream transcriptional region of sarA to virulence in Staphylococcus aureus. Infect Immun 82(10): 4369-4379. doi: 10.1128/IAI.02002-14

306. He H, Cooper JN, Mishra A, Raskin DM (2012). Stringent response regulation of biofilm formation in Vibrio cholerae. J Bacteriol 194(11): 2962-2972. doi: 10.1128/JB.00014-12

307. Petrova OE, Sauer K (2009). A novel signaling network essential for regulating Pseudomonas aeruginosa biofilm development. PLoS Pathog 5(11): e1000668. doi: 10.1371/journal.ppat.1000668

308. Ventre I, Goodman AL, Vallet-Gely I, Vasseur P, Soscia C, Molin S, Bleves S, Lazdunski A, Lory S, Filloux A (2006). Multiple sensors control reciprocal expression of Pseudomonas aeruginosa regulatory RNA and virulence genes. Proc Natl Acad Sci U S A 103(1): 171-176. doi: 10.1073/pnas.0507407103

309. Goodman AL, Merighi M, Hyodo M, Ventre I, Filloux A, Lory S (2009). Direct interaction between sensor kinase proteins mediates acute and chronic disease phenotypes in a bacterial pathogen. Genes Dev 23(2): 249-259. doi: 10.1101/gad.1739009

310. Schurr MJ, Deretic V (1997). Microbial pathogenesis in cystic fibrosis: co-ordinate regulation of heat-shock response and conversion to mucoidy in Pseudomonas aeruginosa. Mol Microbiol 24(2): 411420. doi: 10.1046/j.1365-2958.1997.3411711.x

311. Ramsey DM, Wozniak DJ (2005). Understanding the control of Pseudomonas aeruginosa alginate synthesis and the prospects for management of chronic infections in cystic fibrosis. Mol Microbiol 56(2): 309-322. doi: 10.1111/j.1365-2958.2005.04552.x

312. Govan JR, Deretic V (1996). Microbial pathogenesis in cystic fibrosis: mucoid Pseudomonas aeruginosa and Burkholderia cepacia. Microbiol Rev 60(3): 539-574. doi: 10.1128/mmbr.60.3.539-574.1996

313. Villanueva M, Garcia B, Valle J, Rapun B, Ruiz de Los Mozos I, Solano C, Marti M, Penades JR, Toledo-Arana A, Lasa I (2018). Sensory deprivation in Staphylococcus aureus. Nat Commun 9(1): 523. doi: 10.1038/s41467-018-02949-y

314. Ulrich M, Bastian M, Cramton SE, Ziegler K, Pragman AA, Bragonzi A, Memmi G, Wolz C, Schlievert PM, Cheung A, Doring G (2007). The staphylococcal respiratory response regulator SrrAB induces ica gene transcription and polysaccharide intercellular adhesin expression, protecting Staphylococcus aureus from neutrophil killing under anaerobic growth conditions. Mol Microbiol 65(5): 1276-1287. doi: 10.1111/j.1365-2958.2007.05863.x

315. Pragman AA, Yarwood JM, Tripp TJ, Schlievert PM (2004). Characterization of virulence factor regulation by SrrAB, a two-component system in Staphylococcus aureus. J Bacteriol 186(8): 2430-2438. doi: 10.1128/jb.186.8.2430-2438.2004

316. Cheung AL, Koomey JM, Butler CA, Projan SJ, Fischetti VA (1992). Regulation of exoprotein expression in Staphylococcus aureus by a locus (sar) distinct from agr. Proc Natl Acad Sci U S A 89(14): $6462-$ 6466. doi: $10.1073 /$ pnas.89.14.6462

317. Rechtin TM, Gillaspy AF, Schumacher MA, Brennan RG, Smeltzer MS, Hurlburt BK (1999). Characterization of the SarA virulence gene regulator of Staphylococcus aureus. Mol Microbiol 33(2): 307-316. doi: 10.1046/j.1365-2958.1999.01474.x

318. Tsang LH, Cassat JE, Shaw LN, Beenken KE, Smeltzer MS (2008). Factors contributing to the biofilm-deficient phenotype of Staphylococcus aureus sarA mutants. PLoS One 3(10): e3361. doi: 10.1371/journal.pone.0003361
319. Jager S, Jonas B, Pfanzelt D, Horstkotte MA, Rohde H, Mack D, Knobloch JK (2009). Regulation of biofilm formation by sigma B is a common mechanism in Staphylococcus epidermidis and is not mediated by transcriptional regulation of sarA. Int J Artif Organs 32(9): 584 591. doi: 10.1177/039139880903200907

320. Knobloch JK, Jager S, Horstkotte MA, Rohde H, Mack D (2004). RsbU-dependent regulation of Staphylococcus epidermidis biofilm formation is mediated via the alternative sigma factor sigmaB by repression of the negative regulator gene icaR. Infect Immun 72(7): 3838-3848. doi: 10.1128/IAI.72.7.3838-3848.2004

321. Høiby N, Bjarnsholt T, Moser C, Bassi GL, Coenye T, Donelli G, Hall-Stoodley L, Holá V, Imbert C, Kirketerp-Møller K, Lebeaux D, Oliver A, Ullmann AJ, Williams C (2015). ESCMID guideline for the diagnosis and treatment of biofilm infections 2014. Clin Microbiol Infect 21 (Suppl 1): S1-25. doi: 10.1016/j.cmi.2014.10.024

322. Vassallo M, Dunais B, Roger PM (2015). Antimicrobial lock therapy in central-line associated bloodstream infections: a systematic review. Infection 43(4): 389-398. doi: 10.1007/s15010-015-0738-1

323. Döring G, Flume $P$, Heijerman H, Elborn JS (2012). Treatment of lung infection in patients with cystic fibrosis: Current and future strategies. J Cys Fibros 11(6): 461-479. doi: 10.1016/j.jcf.2012.10.004

324. Malcher J, Wesoly J, Bluyssen HA (2014). Molecular properties and medical applications of peptide nucleic acids. Mini Rev Med Chem 14(5): 401-410. doi: 10.2174/1389557514666140428114613

325. Hancock RE, Haney EF, Gill EE (2016). The immunology of host defence peptides: beyond antimicrobial activity. Nat Rev Immunol 16(5): 321-334. doi: 10.1038/nri.2016.29

326. Paluch E, Rewak-Soroczynska J, Jedrusik I, Mazurkiewicz E, Jermakow K (2020). Prevention of biofilm formation by quorum quenching. Appl Microbiol Biotechnol 104(5): 1871-1881. doi: 10.1007/s00253-020-10349-w

327. Römling U, Galperin MY, Gomelsky M (2013). Cyclic di-GMP: the First 25 Years of a Universal Bacterial Second Messenger. Microbio Mol Biol Rev 77(1): 1. doi: 10.1128/MMBR.00043-12

328. Sambanthamoorthy K, Luo C, Pattabiraman N, Feng X, Koestler B, Waters CM, Palys TJ (2014). Identification of small molecules inhibiting diguanylate cyclases to control bacterial biofilm development. Biofouling 30(1): 17-28. doi: 10.1080/08927014.2013.832224

329. Sharma P, Garg N, Sharma A, Capalash N, Singh R (2019). Nucleases of bacterial pathogens as virulence factors, therapeutic targets and diagnostic markers. Int J Med Microbiol 309(8): 151354. doi 10.1016/j.jimm.2019.151354

330. Blanco-Cabra N, Paetzold B, Ferrar T, Mazzolini R, Torrents E, Serrano L, Lluch-Senar M (2020). Characterization of different alginate lyases for dissolving Pseudomonas aeruginosa biofilms. Sci Rep 10(1): 9390. doi: 10.1038/s41598-020-66293-2

331. Cegelski L, Pinkner JS, Hammer ND, Cusumano CK, Hung CS, Chorell E, Åberg V, Walker JN, Seed PC, Almqvist F, Chapman MR, Hultgren SJ (2009). Small-molecule inhibitors target Escherichia coli amyloid biogenesis and biofilm formation. Nat Chem Biol 5(12): 913-919. doi: 10.1038/nchembio.242

332. Johnston CS, Gaas CA (2006). Vinegar: medicinal uses and antiglycemic effect. MedGenMed 8(2): 61-61. PMID: 16926800

333. Kundukad B, Schussman M, Yang K, Seviour T, Yang L, Rice SA, Kjelleberg S, Doyle PS (2017). Mechanistic action of weak acid drugs on biofilms. Sci Rep 7(1): 4783. doi: 10.1038/s41598-017-05178-3

334. Lin DM, Koskella B, Lin HC (2017). Phage therapy: An alternative to antibiotics in the age of multi-drug resistance. World J Gastrointest Pharmacol Ther 8(3): 162-173. doi: 10.4292/wjgpt.v8.i3.162 
335. Sutherland IW, Hughes KA, Skillman LC, Tait K (2004). The interaction of phage and biofilms. FEMS Microbiol Lett 232(1): 1-6. doi: 10.1016/s0378-1097(04)00041-2

336. Glonti T, Chanishvili N, Taylor PW (2010). Bacteriophage-derived enzyme that depolymerizes the alginic acid capsule associated with cystic fibrosis isolates of Pseudomonas aeruginosa. J Appl Microbiol 108(2): 695-702. doi: 10.1111/j.1365-2672.2009.04469.x

337. Motlagh AM, Bhattacharjee AS, Goel R (2016). Biofilm control with natural and genetically-modified phages. World J Microbiol Biotechnol 32(4): 67. doi: 10.1007/s11274-016-2009-4

338. Wright A, Hawkins $\mathrm{CH}$, Anggård EE, Harper DR (2009). A controlled clinical trial of a therapeutic bacteriophage preparation in chronic otitis due to antibiotic-resistant Pseudomonas aeruginosa; a preliminary report of efficacy. Clin Otolaryngol 34(4): 349-357. doi: 10.1111/j.1749-4486.2009.01973.x

339. Waters EM, Neill DR, Kaman B, Sahota JS, Clokie MRJ, Winstanley C, Kadioglu A (2017). Phage therapy is highly effective against chronic lung infections with Pseudomonas aeruginosa. Thorax 72(7): 666-667. doi: 10.1136/thoraxjnl-2016-209265

340. Seth AK, Geringer MR, Nguyen KT, Agnew SP, Dumanian Z, Galiano RD, Leung KP, Mustoe TA, Hong SJ (2013). Bacteriophage therapy for Staphylococcus aureus biofilm-infected wounds: a new approach to chronic wound care. Plast Reconstr Surg 131(2): 225-234. doi: 10.1097/PRS.0b013e31827e47cd 